


호음 공 完夢 들이윰 홍겅을 유

通号句

\&

모옹

융랄음

국요

零

쿠 궁음

으응 긍

蛋

皇 을

옴 官

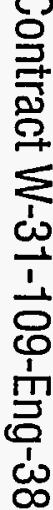

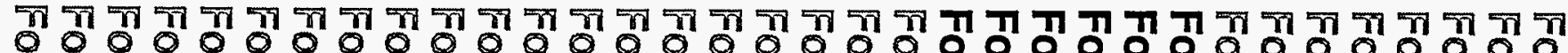
且

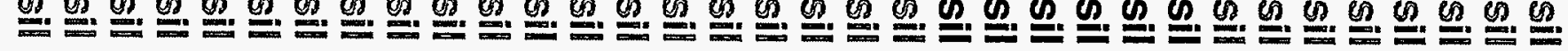

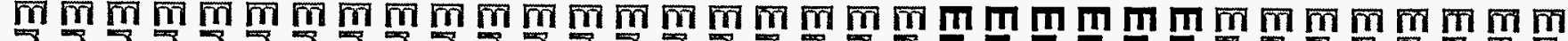

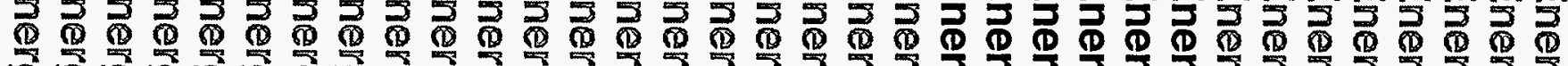
웅 09090909090909 ○



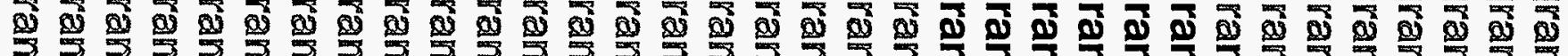

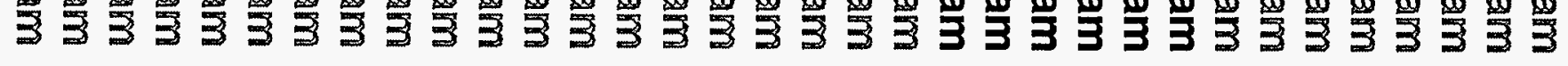

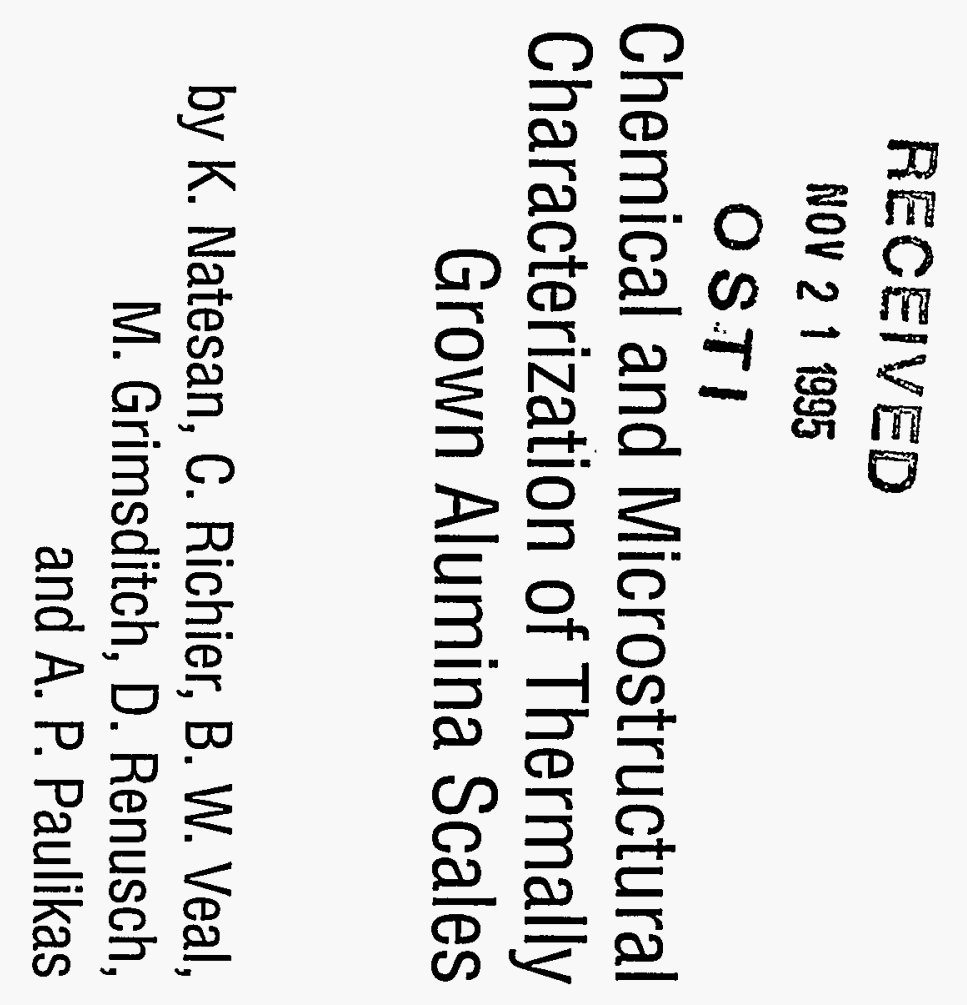

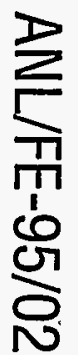


Argonne National Laboratory, with facilities in the states of Illinois and Idaho, is owned by the United States government, and operated by The University of Chicago under the provisions of a contract with the Department of Energy.

\section{DISCLAIMER}

This report was prepared as an account of work sponsored by an agency of the United States Government. Neither the United States Government nor any agency thereof, nor any of their employees, makes any warranty, express or implied, or assumes any legal liability or responsibility for the accuracy, completeness, or usefulness of any information, apparatus, product, or process disclosed, or represents that its use would not infringe privately owned rights. Reference herein to any specific commercial product, process, or service by trade name, trademark, manufacturer, or otherwise, does not necessarily constitute or imply its endorsement, recommendation, or favoring by the United States Government or any agency thereof. The views and opinions of authors expressed herein do not necessarily state or reflect those of the United States Government or any agency thereof.

Reproduced from the best available copy.

Available to DOE and DOE contractors from the

Office of Scientific and Technical Information

P.O. Box 62

Oak Ridge, TN 37831

Prices available from (615) 576-8401

Available to the public from the

National Technical Information Service

U.S. Department of Commerce

5285 Port Royal Road

Springfield, VA 22161 
ANL/FE-95/02

\section{CHEMICAL AND MICROSTRUCTURAL CHARACTERIZATION OF THERMALLY GROWN ALUMINA SCALES}

\section{by}

K. Natesan, C. Richier, B. W. Veal,*

M. Grimsditch,* D. Renusch,* and A. P. Paulikas*

Energy Technology Division

*Materials Science Division

September 1995

Report Prepared by Argonne National Laboratory 9700 South Cass Avenue

Argonne, Illinois 60439 under

Purchase Order Number 10X-SS108V

for

OAK RIDGE NATIONAL LABORATORY

Oak Ridge, Tennessee 37831 managed by

LOCKHEED MARTIN ENERGY SYSTEMS, INC.

for the

U. S. Department of Energy

under Contract No. DE-AC05-84ORं21400

DISTABBUTION OF THIS DOCUMENT IS UNLIMITED 



\section{CONTENTS}

Abstract

Introduction 1

Experimental Program....................................................................................................................... 3

Materials........................................................................................................................................ 3

Experimental Procedure ............................................................................................................... 4

Results and Discussion........................................................................................................................ 5

Oxidation Studies..................................................................................................................... 5

Sulfur Segregation Studies........................................................................................................ 11

Raman Spectroscopy/Ruby Fluorescence Studies.....................................................16

Plasma-Deposited Alumina..........................................................................................19

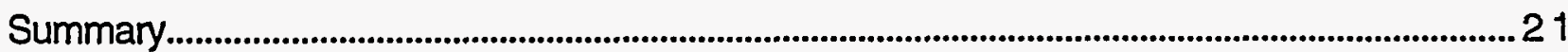

Acknowledgments .................................................................................................................................. 21

References........................................................................................................................................... 22

\section{FIGURES}

1. Weight change data for several $\mathrm{Fe}$ aluminide alloys tested in air at $1000^{\circ} \mathrm{C}$

2. SEM photomicrographs of surfaces of FA 71 and FA 129 alloys tested in air at $1000^{\circ} \mathrm{C}$

3. SEM photomicrographs of surfaces of FAX and FAL alloys tested in air at $1000^{\circ} \mathrm{C}$.

4. EDX spectra for air-exposed FAL specimen in Fig. 3 in center of nodule, scale away from nodule, and periphery of nodule.

5. SEM photomicrographs of cross sections of several $\mathrm{Fe}$ aluminide alloys tested in air at $1000^{\circ} \mathrm{C}$.

6. Weight change data for several $\mathrm{Fe}$ aluminide alloys tested in pure oxygen at $1000^{\circ} \mathrm{C}$

7. SEM photomicrographs of surfaces of FA 61, FA 71, and FA 129 alloys tested in oxygen at $1000^{\circ} \mathrm{C}$

8. SEM photomicrographs of surfaces of FAX and FAL alloys tested in oxygen at $1000^{\circ} \mathrm{C}$

9. AES spectra for FA 71 specimen in initial condition and after $10 \mathrm{~min}$, 5 , and $10 \mathrm{~h}$ of exposure to high-purity argon at $1000^{\circ} \mathrm{C}$

10. Elemental depth profiles obtained by AES analysis for several specimens.

11. Variation in concentration of $\mathrm{Fe}, \mathrm{Al}, \mathrm{O}$, and $\mathrm{S}$ on surfaces of $\mathrm{FA} 71$ alloy as a function of exposure time in argon at $1000^{\circ} \mathrm{C}$. 
12. SEM photomicrographs of surfaces of FA 71 exposed in argon at $1000^{\circ} \mathrm{C}$ for $10 \mathrm{~min}, 1 \mathrm{~h}$, and $5 \mathrm{~h}$.

13. SEM photomicrographs of surfaces of FA 71 exposed in argon at $1000^{\circ} \mathrm{C}$ for $10 \mathrm{~h}, 10 \mathrm{~h}$ plus polished and re-exposed for $5 \mathrm{~h}$, and $10 \mathrm{~h}$ plus re-exposure step

14. Raman spectroscopy data obtained for FA 71 alloy after oxidation in air at several temperatures.

15. Raman intensity data for $\mathrm{Fe}_{2} \mathrm{O}_{3}$ from $\mathrm{FA} 71$ and ruby fluorescence data for FA 71 and FAL, as a function of oxidation temperature.

16. Data on ruby line peak shift vs. oxidation temperature for FA 71 and FAL alloys

17. Strain in thermally grown alumina scales in several alloys as a function of exposure temperature

18. RBS spectrum for $\approx 0.5-\mu \mathrm{m}$ layer of plasma-deposited alumina 20

19. X-ray diffraction data for $\approx 0.5-\mu \mathrm{m}$ layer of plasma-deposited alumina

20. SEM photomicrographs of specimen with plasma-deposited alumina in as-deposited condition, after exposure to air at $1000^{\circ} \mathrm{C}$, and thermally grown alumina at $1000^{\circ} \mathrm{C}$ in air

\section{TABLES}

1. Chemical composition of alloys used in oxidation tests ................................... 4

2. Rate constants for oxidation of $\mathrm{Fe}$ aluminide alloys............................................. 6 


\title{
CHEMICAL AND MICROSTRUCTURAL CHARACTERIZATION OF THERMALLY GROWN ALUMINA SCALES*
}

\author{
by \\ K. Natesan, C. Richier, B. W. Veal, ${ }^{*}$ \\ M. Grimsditch, ${ }^{*}$ D. Renusch, ${ }^{*}$ and A. P. Paulikas* \\ Energy Technology Division \\ *Materials Science Division
}

\begin{abstract}
An experimental program has been initiated to evaluate the chemical, microstructural, and mechanical integrity of thermally grown oxide scales to establish requirements for improved corrosion performance in terms of composition, structure, and properties. Iron aluminides of several compositions were selected for the study. Oxidation studies were conducted in air and oxygen environments at $1000^{\circ} \mathrm{C}$. The results showed that the scaling kinetics followed a parabolic rate law but that the rates in early stages of oxidation were significantly greater than in later stages; the difference could be attributed to the presence of fast-growing transient iron oxides in the layer during the early stages. Further, scale failure occurred via gross spallation, scale cracking, and nodule formation and was influenced by alloy composition. Auger electron spectroscopy of Ar-exposed specimens of ternary Fe-Cr-Al alloy showed sulfur on the gas/scale side of the interface; the sulfur decreased as the exposure time increased. Raman spectroscopy and ruby fluorescence were used to examine the scale development as a function of oxidation temperature. . Ruby-line shift is used to examine phase transformations in alumina and to calculate compressive strains in thermally grown scales.
\end{abstract}

\section{INTRODUCTION}

Corrosion is widely recognized as technologically very important, but an understanding of the underlying phenomena (in order to characterize material performance) covers factors such as the chemistry and physics of the early stages of oxidation, chemistry and bonding at the substrate/oxide interface, role of segregants in the strength of that bond, transport processes through corrosion scale, mechanisms of residual stress generation and relief, and fracture behavior at the oxide/substrate interface. Because of this complexity and the need for a wide range of different techniques, a multilaboratory program has been initiated under the auspices of the U.S. Department of Energy (DOE) Center of Excellence for the Synthesis and Processing of Advanced Materials, with strong interactions and cross-leveraging with the DOE Fossil Energy program and U.S. industry. The

\footnotetext{
-Research sponsored by the U.S. Department of Energy, Advanced Research and Technology Development Materials Program, DOE/FE AA 151010 0, Work Breakdown Structure Element ANL-4(A).
} 
ultimate objective is the systematic generation of the knowledge required to establish a scientific basis for designing and synthesizing improved protective oxide scales/coatings (slow-growing, adherent, and sound) on high-temperature materials without compromising the requisite properties of the bulk materials. The objectives of work at Argonne National Laboratory are to (a) correlate actual corrosion performance with stresses, voids, segregants, interface roughness, initial stages of oxidation, and microstructures; (b) study such behavior in growing or as-grown films; and (c) define prescriptive designs and synthesis routes that lead to mechanically reliable surface oxides.

Protection from corrosion and environmental effects that arise from reactions with gases and condensed products is required in order to fully exploit the potential of advanced high-temperature materials that are designed to improve energy efficiency and minimize deleterious environmental impact. This protection is best afforded by either formation of stable surface oxides that are slow growing, sound, and adherent to the substrate, or deposition of coatings that contain or develop oxides with similar characteristics. Several theories have been proposed to explain the enhanced adhesion of oxide scale on metal substrates when reactive and/or rare-earth elements are added to the alloys: 1

- Rare earth or reactive-element atoms act as vacancy sinks and thereby minimize vacancy condensation at the scale/metal interface.

- Oxide pegs grow from the oxide scale down to the substrate, increasing the adherence.

- Addition of reactive and/or rare-earth elements improves plasticity of the scale, leading to better adherence at elevated temperatures.

- These reactive and/or rare-earth elements improve chemical bonding between the oxide scale and the substrate.

- These elements form an intermediate barrier layer between the scale and the substrate that can minimize the transport of cations and anions across the interface and also better accommodate strain induced by thermal stresses.

- The alloying additions minimize segregation of tramp elements such as $\mathrm{S}$ at the scale/metal interface and thereby improve adhesion.

Data in the literature indicate that all of the above theories are applicable, depending on the alloy composition, the amount and type of alloying addition, exposure temperature, thermal cycling conditions, and time of exposure. Among the theories, gettering of $S$ has received significant attention in recent years. Reactive and rare-earth elements, which generally have a strong thermodynamic affinity for $S$, can react to fix the $S$ as innocuous sulfide particles in the alloy and thereby minimize weakening of the scale/metal interface bonding and improve adhesion. ${ }^{1-3}$ Elements such as $\mathrm{Zr}, \mathrm{Y}, \mathrm{Ce}$, and $\mathrm{La}$ will form sulfides that 
are more stable than those of base metal elements (such as $\mathrm{Fe}, \mathrm{Cr}$, and $\mathrm{Ni}$ ) and have been shown to improve scale adhesion in Fe-Cr-Al alloys. Addition of $\mathrm{Zr}$ and $\mathrm{Nb}$ to $\mathrm{Fe}-\mathrm{Cr}-\mathrm{Ni}$ alloys have improved the oxidation resistance of these alloys by forming a barrier layer of refractory metal oxide at the chromia/substrate interface and by gettering the $S$ in the alloy. 4

The benefits of various alloying additions to the growth and adherence of protective oxide scales on metallic substrates are well known, but we still need a detailed understanding of the mechanisms by which scale properties (both chemical and mechanical) and coating integrity are improved by modifications in composition, microstructure, and processing. The design and synthesis of optimal scales and coatings for high-temperature protection must ultimately rely on information about the

- Surface physics of the initial stages of the oxidation process.

- Chemistry and bonding at the substrate/oxide interface and the role of segregants in the strength of that bond.

- Mechanisms and levels of residual stress generation and relief.

- Damage accumulation mechanisms within the oxide scale/coating.

- Role of segregants in the strength of grain boundaries within the oxide layer.

- Fracture behavior of the scale/coating and the oxide/substrate interface.

The present experimental study has focused on Fe aluminide alloys, which are of interest in fossil energy applications. The aluminide alloys, which are alumina formers, are in various stages of development under the sponsorship of the DOE Fossil Energy program. These alloys can be used as either structural material or as a cladding to protect structural material against corrosion. In addition, plasma-deposited alumina coatings on iron aluminide substrates are being examined for their microstructures and mechanical integrity at elevated temperatures. Several techniques, including Auger electron spectroscopy, X-ray diffraction, $X$-ray grazing incidence reflectance, grazing-angle $X$-ray fluorescence, optical fluorescence, and Raman spectroscopy, are used in the studies. This report presents results obtained from studies on the early stages of oxidation and the surface segregation of trace elements in alumina-forming alloys. The results of these examinations will be compared with those from thermally grown alumina scales.

\section{EXPERIMENTAL PROGRAM}

\section{MATERIALS}

Sheets of several FezAl-based alloys were procured from Oak Ridge National Laboratory. Table 1 lists the compositions of the alloys used in the study. The 
sheet materials were given either a single annealing treatment at $750^{\circ} \mathrm{C}$ for $1 \mathrm{~h}$, followed by oil quenching, or a dual annealing treatment for $1 \mathrm{~h}$ at $850^{\circ} \mathrm{C}$ and 7 days at $500^{\circ} \mathrm{C}$. For oxidation and segregation studies, $8 \times 6 \times 0.5-1.0 \mathrm{~mm}$ test coupons were cut from sheets of the alloys. Iron aluminide specimens with plasma-deposited alumina were obtained from Lawrence Berkeley Laboratory for characterization of the deposited coatings, which were $\approx 0.5 \mu \mathrm{m}$ thick and exhibited an adhesion strength of $>70 \mathrm{MPa}$.

Table 1. Chemical composition (in wt.\%) of alloys used in oxidation tests

\begin{tabular}{lcclc}
\hline Material & Cr & Al & Fea & Other \\
\hline FA 61 & - & 15.9 & Bal. & - \\
FA 71 & 5.5 & 15.9 & Bal. & - \\
FA 81 & 2.2 & 15.9 & Bal. & B 0.01 \\
FA 129 & 5.5 & 15.9 & Bal. & Nb 1.0, C 0.05 \\
FAX & 5.5 & 15.9 & Bal. & Nb 1.0, Mo 1.0, Zr 0.15, B 0.04 \\
FAL & 5.5 & 15.9 & Bal. & Zr 0.1, B 0.05 \\
FAS & 2.2 & 15.9 & Bal. & B 0.05 \\
\hline
\end{tabular}

aBal. = balance

\section{EXPERIMENTAL PROCEDURE}

Several types of experiments were initiated to examine the oxidation behavior of these alloys, with emphasis on early stages of scaling, microstructural changes in scales, trace-element segregation on the free surface and scale/alloy interface, and adhesion and scale spallation characteristics. To establish the effect of alloy composition on long-term oxidation characteristics and scaling kinetics, thermogravimetric experiments were performed at $1000^{\circ} \mathrm{C}$ with an electrobalance having a sensitivity of $0.1 \mu \mathrm{g}$. Specimens were suspended from the balance in a vertical furnace and held for the desired exposure period. Ultrahigh-purity air, further purified by passing over a hot bed of Zr chips, was used in these experiments. Upon completion of the oxidation test, the furnace was opened and the specimen was rapidly cooled in high-purity air. Following thermogravimetric measurement of oxidation, the scale surfaces and specimen cross sections were examined with a scanning electron microscope equipped with an energy-dispersive X-ray (EDX) analyzer.

For the segregation studies, specimens of FA 71 alloy were exposed at $1000^{\circ} \mathrm{C}$ to high-purity $\mathrm{Ar}$ for $10 \mathrm{~min}$ and 1,5 , and $10 \mathrm{~h}$. Subsequently, the specimens were analyzed by Auger electron spectroscopy (AES), and by sputtering, to obtain AES spectra and depth profile analyses for $\mathrm{Fe}, \mathrm{Cr}, \mathrm{Al}, \mathrm{O}$, and S. For Raman and fluorescence spectroscopy studies, specimens of FA 71 and FAL alloys were used to examine scale composition during scale development and evaluate the effect of exposure temperature on scale adhesion and spallation. 
Raman spectroscopy studies were used to identify and monitor the evolution of $\mathrm{Fe}_{2} \mathrm{O}_{3}$ and $\mathrm{Al}_{2} \mathrm{O}_{3}$ in scales grown on $\mathrm{FA} 71$ and $\mathrm{FAL}$ after sequential treatments in air at temperatures ranging from 300 to $1300^{\circ} \mathrm{C} .5$ These sesquioxides can be readily identified from Raman spectra by using the measurements as a "fingerprint" technique. Evidence of additional oxide phases in the scales is present in the spectra, but their identification is not straightforward. Further, some line broadening and spectral-line shifts are present (possibly because of strains or impurity effects) but the data are preliminary and additional tests are being conducted to further explore this technique.

The FA 71 and FAL alloys are alumina formers. However, the alumina scales that develop on these alloys after high-temperature oxidation contain a small amount of dissolved $\mathrm{Cr}$. When 3d electrons of $\mathrm{Cr}$, from atoms substituting on $\mathrm{Al}$ sites, are excited, they de-excite by producing a sharp fluorescence doublet with a wavelength near $7000 \AA$. (The red gemstone ruby is a Cr-doped alumina; the red coloration comes from the $\mathrm{Cr}$ fluorescence.) As alumina scales form on the iron aluminides, the $\mathrm{Cr}$ fluorescence doublet becomes very prominent. Depending on scale-growth conditions, the doublet shifts and broadens, apparently as a consequence of varying strains in the alumina scale. The shifts provide a sensitive measure of strain accumulation in the scales and clearly indicate when strain relief occurs.

\section{RESULTS AND DISCUSSION}

\section{OXIDATION STUDIES}

Figure 1 shows oxidation data for several of the alumina-forming alloys at $1000^{\circ} \mathrm{C}$ in air. Oxygen uptake by the alloys is fairly rapid in the initial $10 \mathrm{~h}$, after which the rate of weight change was greatly reduced. Some of the alloys, such as FA 61 and FA 71, exhibited extensive spallation when cooled to room temperature. On the other hand, alloys such as FAL and FA 129 developed fairly adherent oxide scales in similar experiments. Table 2 lists the parabolic rate constants obtained for several of the alloys over different exposure times in air. The results indicate that the process does not follow a parabolic behavior over the entire exposure time. Several studies have been conducted on the oxidation of $\mathrm{Fe}$ Al binary alloys with varying $\mathrm{Al}$ concentrations and $\mathrm{Fe}$ aluminide intermetallic compounds.5,6 These studies show that the parabolic rate constant in the initial stages of oxidation is substantially higher than in the later stages of oxidation. The initial rates can be 3-5 times higher than the rates at later stages. Absolute values for the rates obtained in the present $1000^{\circ} \mathrm{C}$ study are somewhat greater than in the earlier studies conducted at $800-900^{\circ} \mathrm{C}$. The initial stages, which are generally a few hours in duration, are dominated by development of scales consisting of transient iron oxides in addition to alumina. However, alloys with $>7 \mathrm{wt} . \% \mathrm{Al}$ seem to develop continuous alumina scale over longer periods of exposure. The aluminide specimens used in the present program contain $>15 \mathrm{wt}$.\% Al but still exhibit a higher initial rate, indicating the presence of transient oxides in the early stages of oxidation. ${ }^{7}$ 


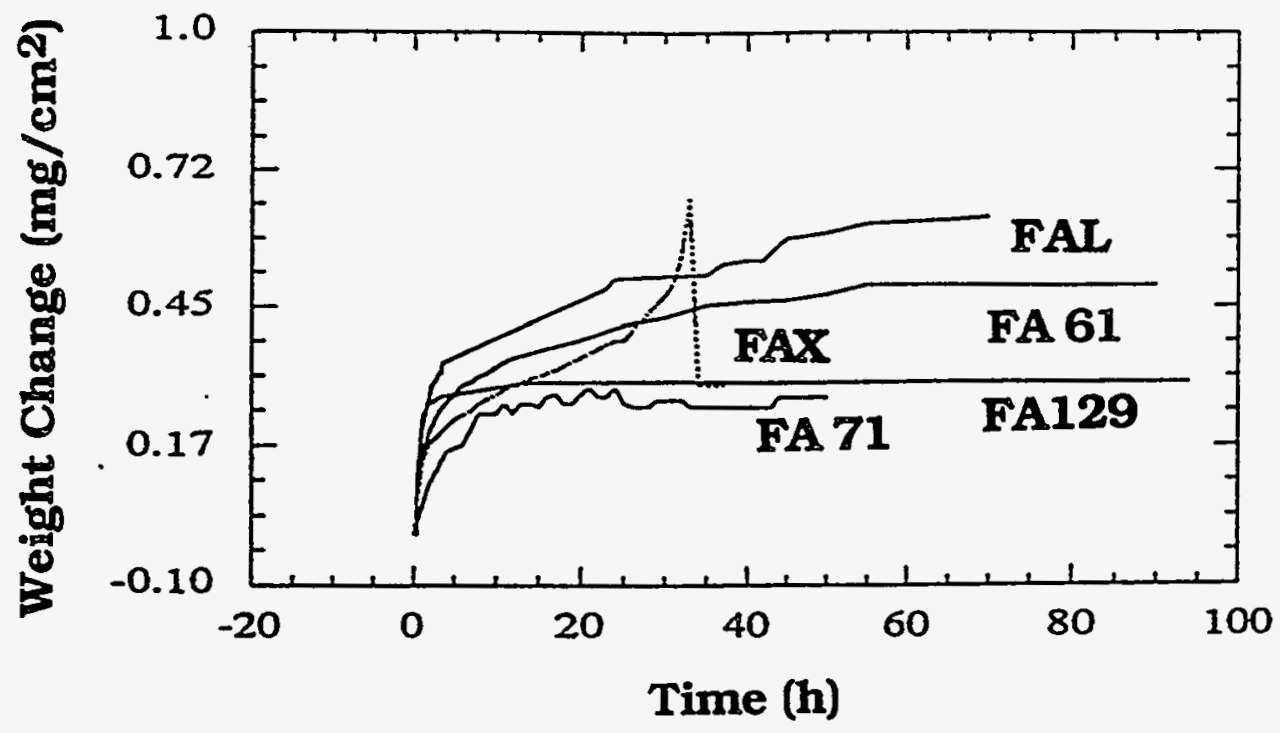

Fig. 1. Weight change data for several $\mathrm{Fe}$ aluminide alloys tested in air at $1000^{\circ} \mathrm{C}$.

Table 2. Rate constants for oxidation of $\mathrm{Fe}$ aluminide alloys

\begin{tabular}{|c|c|c|c|c|}
\hline \multirow[b]{2}{*}{ Alloy } & \multicolumn{2}{|c|}{ Oxidation in Air } & \multicolumn{2}{|c|}{ Oxidation in Oxygen } \\
\hline & $\begin{array}{l}\text { Exposure } \\
\text { time (h) }\end{array}$ & $\begin{array}{c}\mathrm{Kp} \\
\left(10^{-6} \mathrm{mg}^{2} / \mathrm{cm}^{4} \mathrm{~s}\right)\end{array}$ & $\begin{array}{l}\text { Exposure } \\
\text { time (h) }\end{array}$ & $\begin{array}{c}\mathrm{Kp} \\
\left(10^{-6} \mathrm{mg}^{2} / \mathrm{cm}^{4} \mathrm{~s}\right)\end{array}$ \\
\hline \multirow[t]{2}{*}{ FA 61} & $0.5<t<1.5$ & 8.1 & $15<t<40$ & 3.9 \\
\hline & $4<t<12$ & 1.7 & $60<t<80$ & 5.8 \\
\hline FA 71 & $1<t<8$ & 1.9 & $0.5<\dot{\mathrm{t}}<2$ & 1.7 \\
\hline \multirow[t]{2}{*}{ FAX } & $0.5<1.5$ & 6.9 & $1<t<1.8$ & 1.0 \\
\hline & $4<t<20$ & 1.3 & • & \\
\hline \multirow[t]{2}{*}{ FA 129} & $0.5<t<1.3$ & 15 & $0.4<t<1.6$ & 15 \\
\hline & & & $2<t<6$ & 3 \\
\hline \multirow[t]{2}{*}{ FAL } & $3<t<5$ & 20 & $0.5<t<2$ & 17 \\
\hline & & & $20<t<55$ & 1.2 \\
\hline
\end{tabular}

Figures 2 and 3 show scanning electron microscopy (SEM) photomicrographs of surfaces of various alloys exposed to air at $1000^{\circ} \mathrm{C}$. The ternary alloy $F A 71$ exhibited severe scale spallation, whereas alloys such as FA 129, FAX, and FAL exhibited adherent alumina scales with several locally spalled regions on the alloy surface. Scale breakdown in the FAL alloy occurs by formation of Fe-rich nodules, which were widely distributed on the scale surface. Detailed EDX 
analysis (see Fig. 4) showed that the region far away (Fig. 4a) from the nodule consisted of pure alumina. The center of the nodule (Fig. 4b) contained $\mathrm{Fe}, \mathrm{Al}, \mathrm{Zr}$, $\mathrm{Cr}$, and $\mathrm{O}$, indicating a complex oxide, whereas a lower $\mathrm{Fe}$ content is noted in regions between the center of the nodule and the pure alumina scale (Fig. 4c). Nodules of iron oxide have been observed in earlier studies on binary $\mathrm{Fe}-\mathrm{Al}$ alloys containing 2.4 and $6.9 \mathrm{wt} . \% \mathrm{Al}$, after oxidation at $800^{\circ} \mathrm{C}$ in air. 5 However, no nodules were observed in alloys containing $>6.9 \mathrm{wt} . \% \mathrm{Al}$ and the scale consisted predominantly of alumina. In contrast, all the $\mathrm{Fe}$ aluminide alloys used in the present study contained $>15 \mathrm{wt} . \% \mathrm{Al}$ and exhibited alumina scale upon oxidation. The mode of scale cracking was different in each alloy, indicating that alloy composition may play a significant role in scale development, scale cracking, and subsequent spallation. Gross spallation of the scale occurred in FA 71 and FA 129 alloys, while scale cracking via nodule formation occurred in FAX and FAL alloys. Figure 5 contains cross-sectional SEM photomicrographs that display the thickness and morphology of scales developed in the alloys after $100 \mathrm{~h}$ of exposure at $1000^{\circ} \mathrm{C}$.
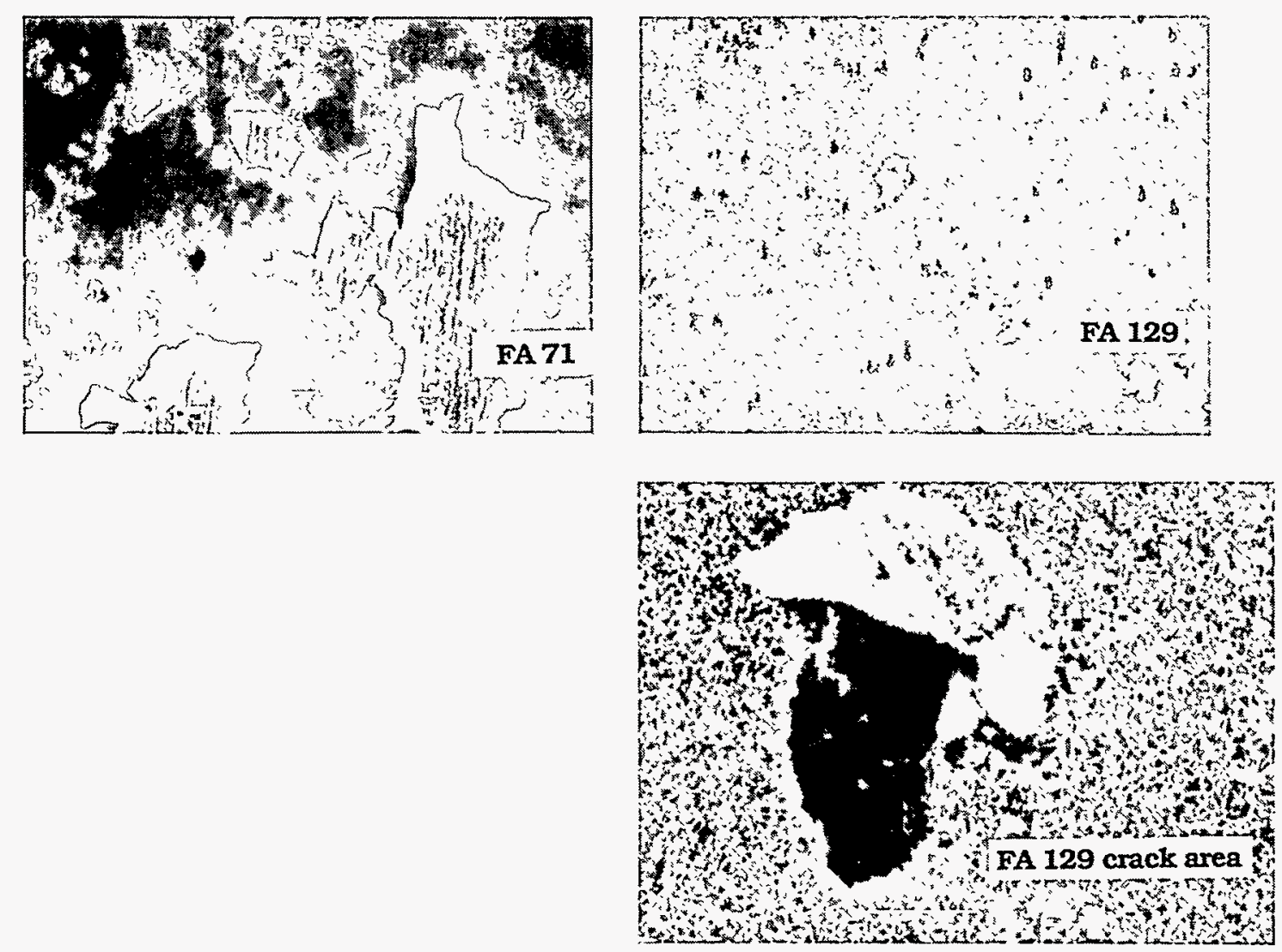

Fig. 2. SEM photomicrographs of surfaces of FA 71 and FA 129 alloys tested in air at $1000^{\circ} \mathrm{C}$. 

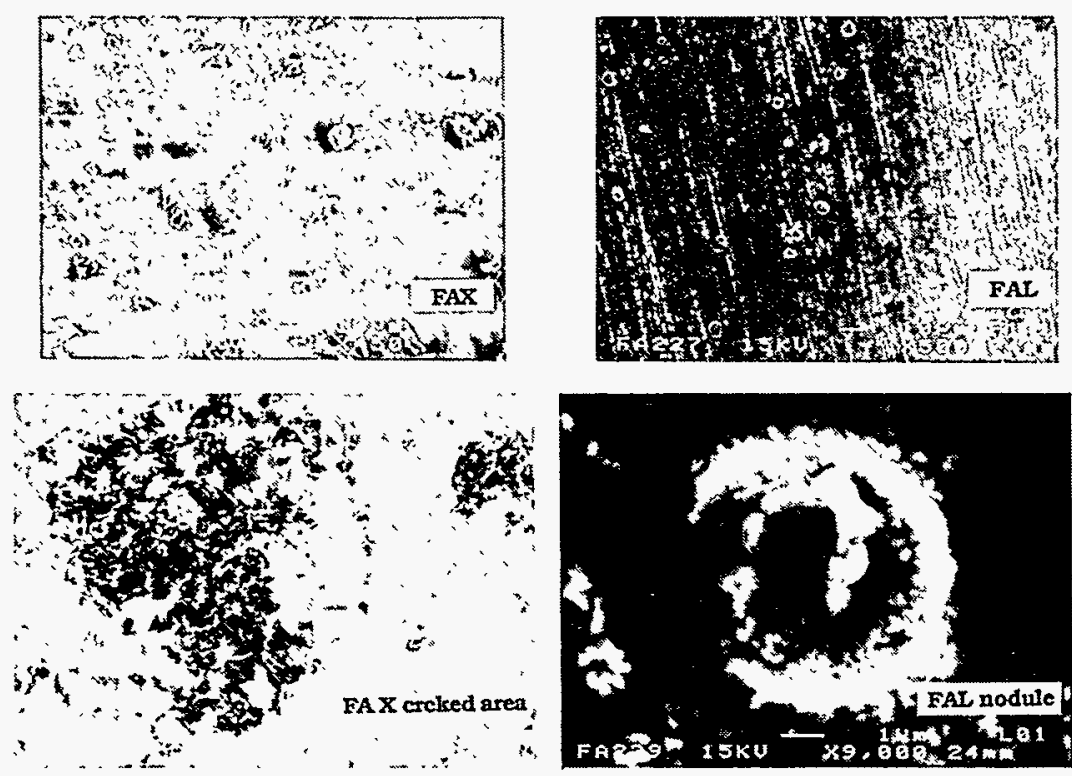

Fig. 3. SEM photomicrographs of surfaces of FAX and FAL alloys tested in air at $1000^{\circ} \mathrm{C}$.

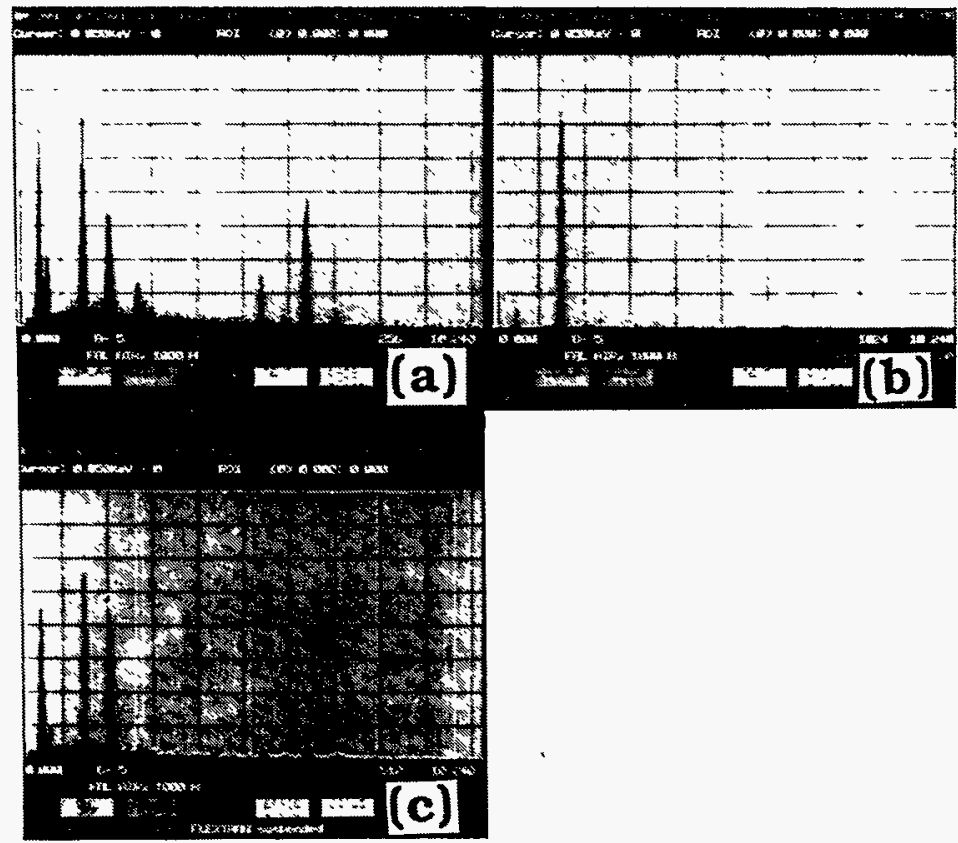

Fig. 4. EDX spectra for air-exposed FAL specimen in Fig. 3 in (a) center of nodule, (b) scale away from nodule, and (c) periphery of nodule. 

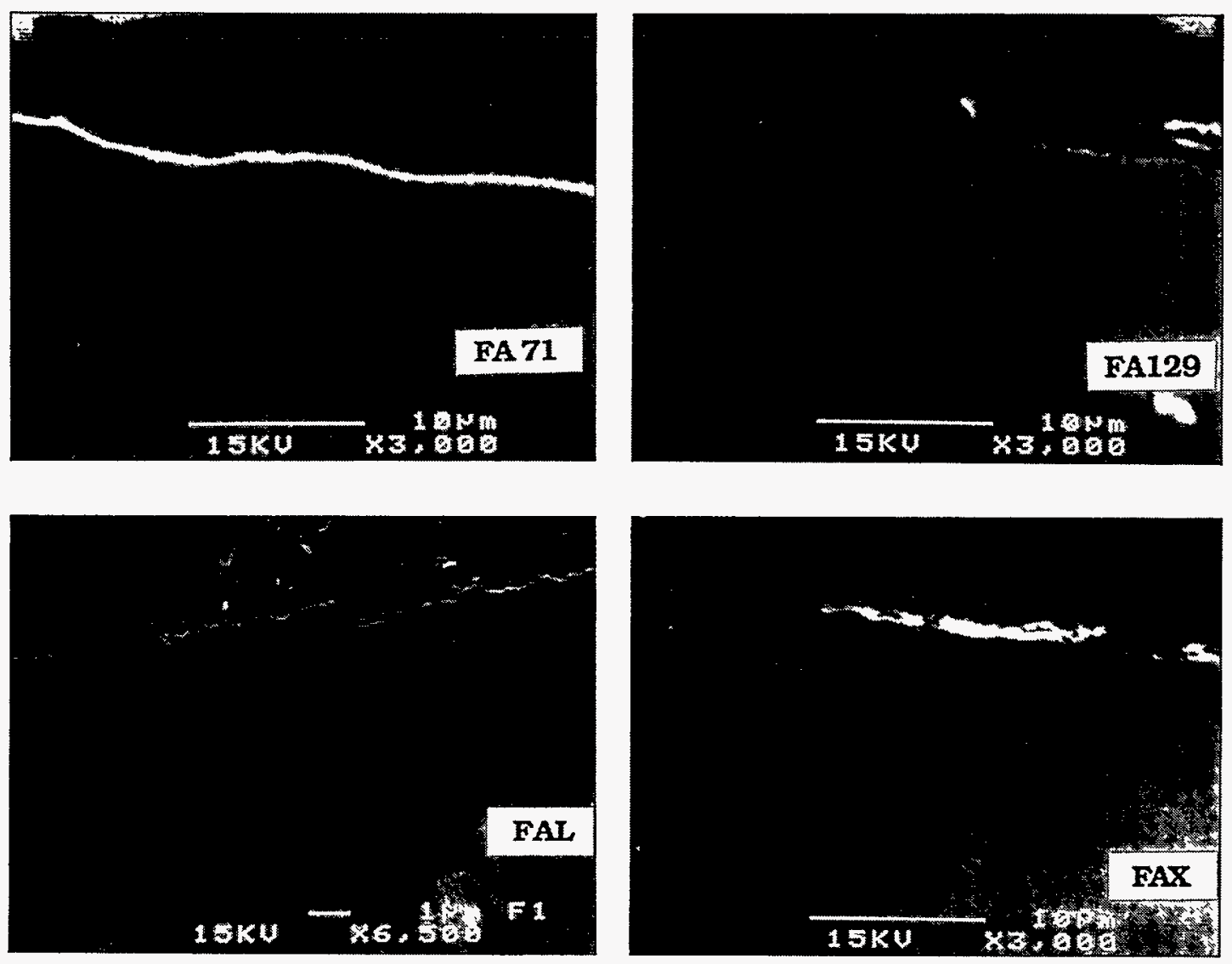

Fig. 5. SEM photomicrographs of cross sections of several $\mathrm{Fe}$ aluminide alloys tested in air at $1000^{\circ} \mathrm{C}$.

Oxidation data obtained from alloys exposed in a pure $O$ environment at $1000^{\circ} \mathrm{C}$ are shown in Fig. 6 . As in air, the $O$ uptake behavior of the alloys increased in the initial period of $1-10 \mathrm{~h}$, after which the rate substantially decreased. Table 2 also lists rate constants obtained for several of the alloys in $O$, calculated from weight change data over different time spans. Figures 7 and 8 show SEM photomicrographs of surfaces of various alloys exposed to $O$ at $1000^{\circ} \mathrm{C}$. As in the air-exposed specimens, all of the alloys show some mode of degradation that involved scale cracking, spallation, and/or nodule formation. The scaling process and the scale morphologies in different alloys seem to differ, even though all of the alloys exhibited similar rapid weight gains in the early stages, with a plateau in the later stages. It seems evident that even under isothermal oxidation conditions, oxidation performance of the alloys is influenced by the early stages of oxidation, which, in turn, are dependent on the alloy composition. 


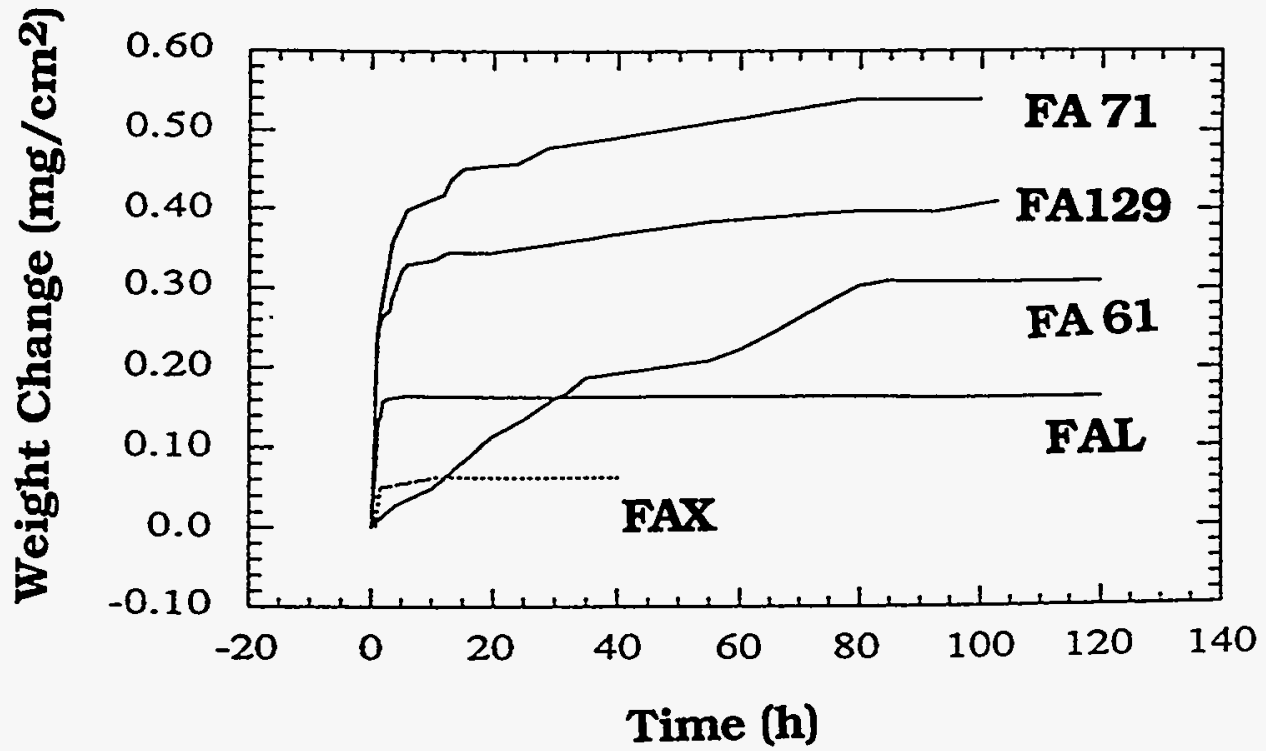

Fig. 6. Weight change data for several $\mathrm{Fe}$ aluminide alloys tested in pure oxygen at $1000^{\circ} \mathrm{C}$.
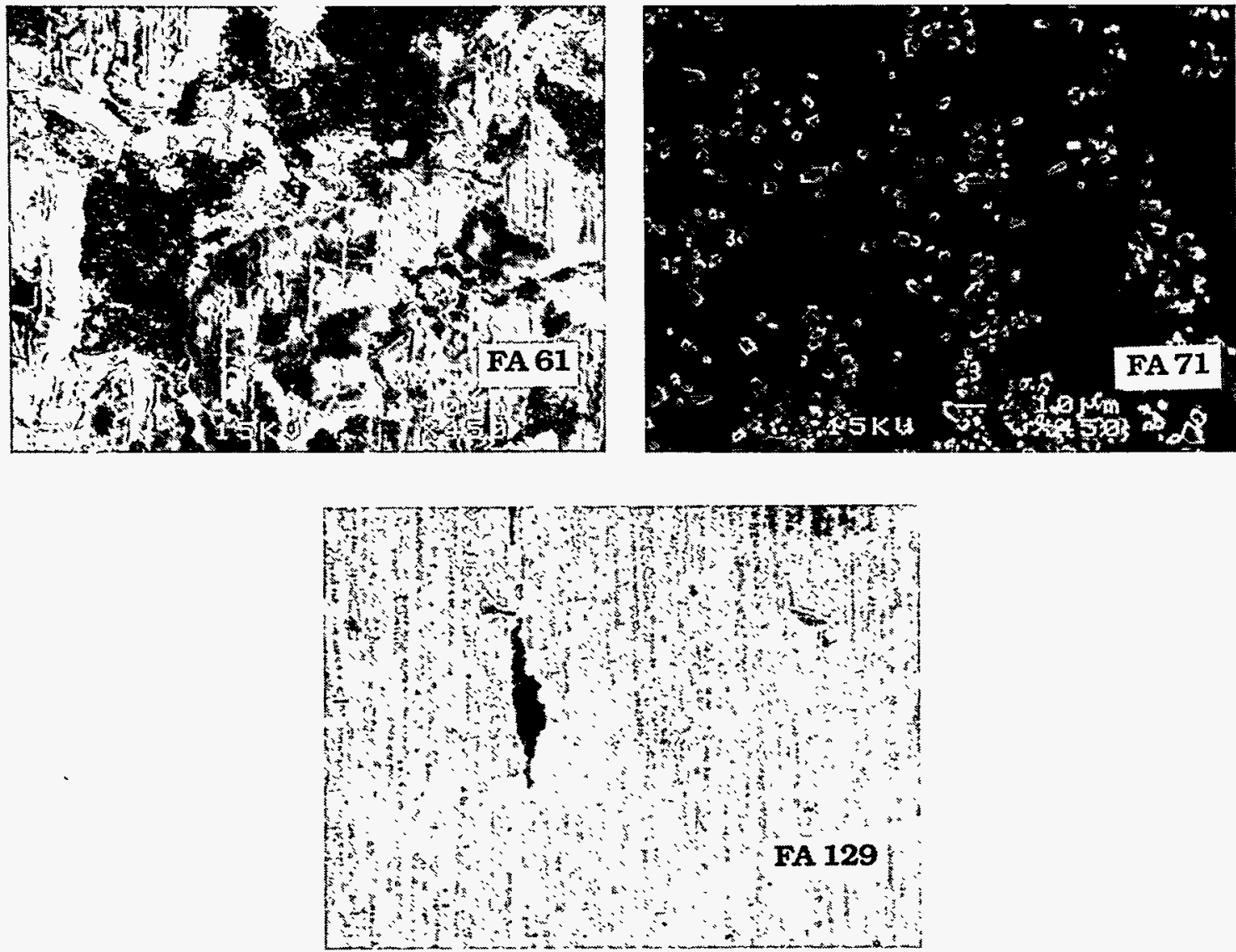

Fig. 7. SEM photomicrographs of surfaces of FA 61, FA 71, and FA 129 alloys tested in oxygen at $1000^{\circ} \mathrm{C}$. 

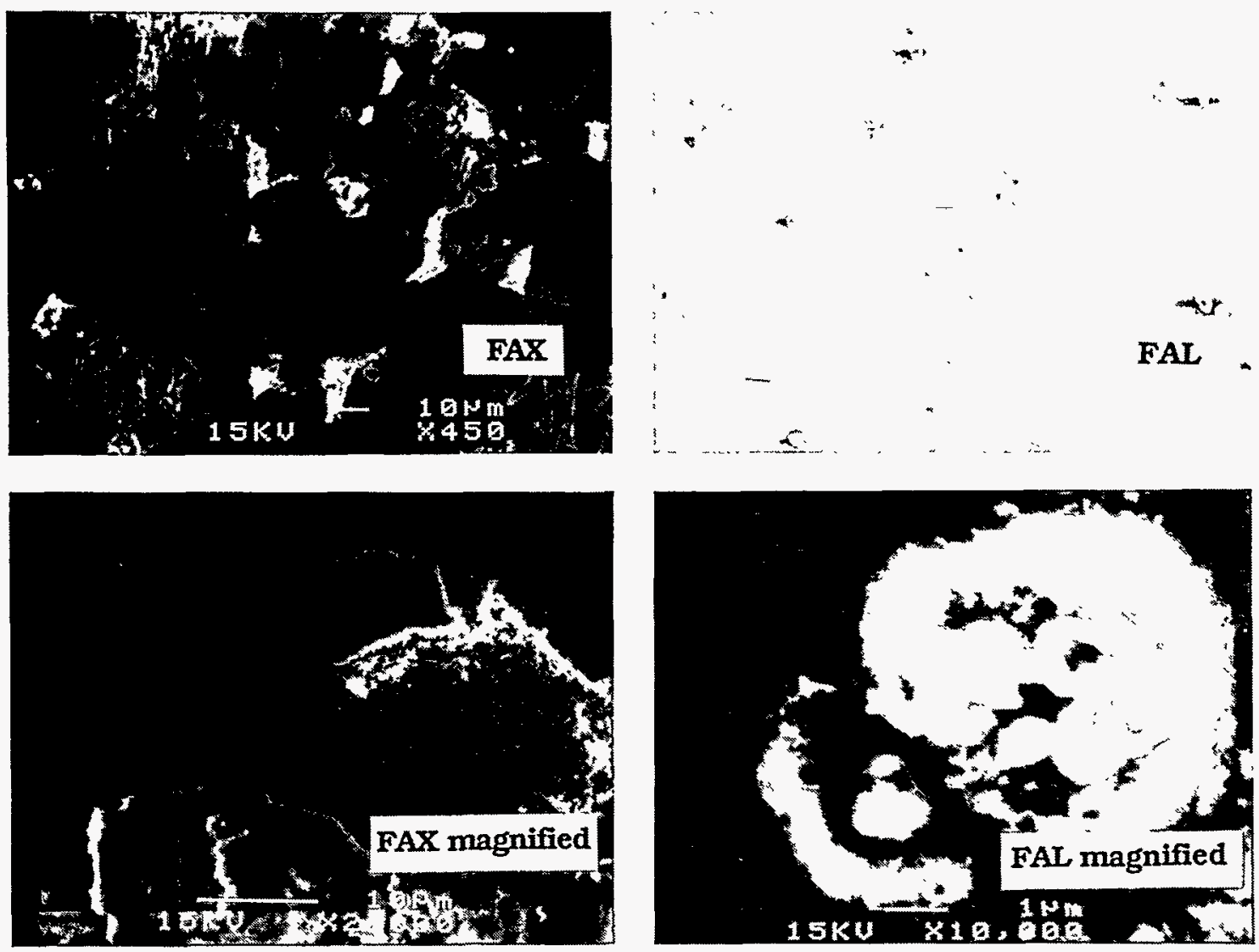

Fig. 8. SEM photomicrographs of surfaces of FAX and FAL alloys tested in oxygen at $1000^{\circ} \mathrm{C}$.

\section{SULFUR SEGREGATION STUDIES}

The AES spectra of FA 71 specimens in the initial condition and after 10 min, and 1,5 , and $10 \mathrm{~h}$ of exposure to high-purity $\mathrm{Ar}$ at $1000^{\circ} \mathrm{C}$ are shown in Fig. 9. The Ar contains sufficient $O$ to permit sustained scale growth. It is evident that the surface of the untreated specimen reveals $S$ and that the peak height for $S$ decreases as the exposure time increases from 0 to $1 \mathrm{~h}$. Although $S$ is absent in the specimen exposed for $5 \mathrm{~h}$, a significant $S$ peak can be observed in the specimen exposed for $10 \mathrm{~h}$. Figure 10 shows the elemental depth profiles obtained by AES analysis for several of the specimens. It is evident that after 10 min of exposure, the scale contained significant $F e$ but that the $A l$ and $O$ concentrations increased to a depth of $\approx 500 \AA$. After $1 \mathrm{~h}$ of exposure in $\mathrm{Ar}, \mathrm{Fe}$ content in the scale decreased significantly, to a depth of $\approx 4000 \AA$. Further increase in exposure time to $5 \mathrm{~h}$ resulted in almost pure alumina scale of $\approx 5000$ $\AA$ thickness. Exposure for $10 \mathrm{~h}$ resulted in destruction of the pure alumina scale, and the elemental depth profiles were similar to those obtained after a 10-min exposure of the virgin alloy. These preliminary results indicate that there may be a critical oxide thickness in alumina-forming alloys that can lead to spallation after cycling to room temperature, and that this thickness may be achieved with exposure times of $5-10 \mathrm{~h}$ at $1000^{\circ} \mathrm{C}$. The observed behavior of scaling and spallation may also be due to segregation of $S$, initially at the alloy surface, to the scale/alloy interface, which can lead to debonding of the scale. 

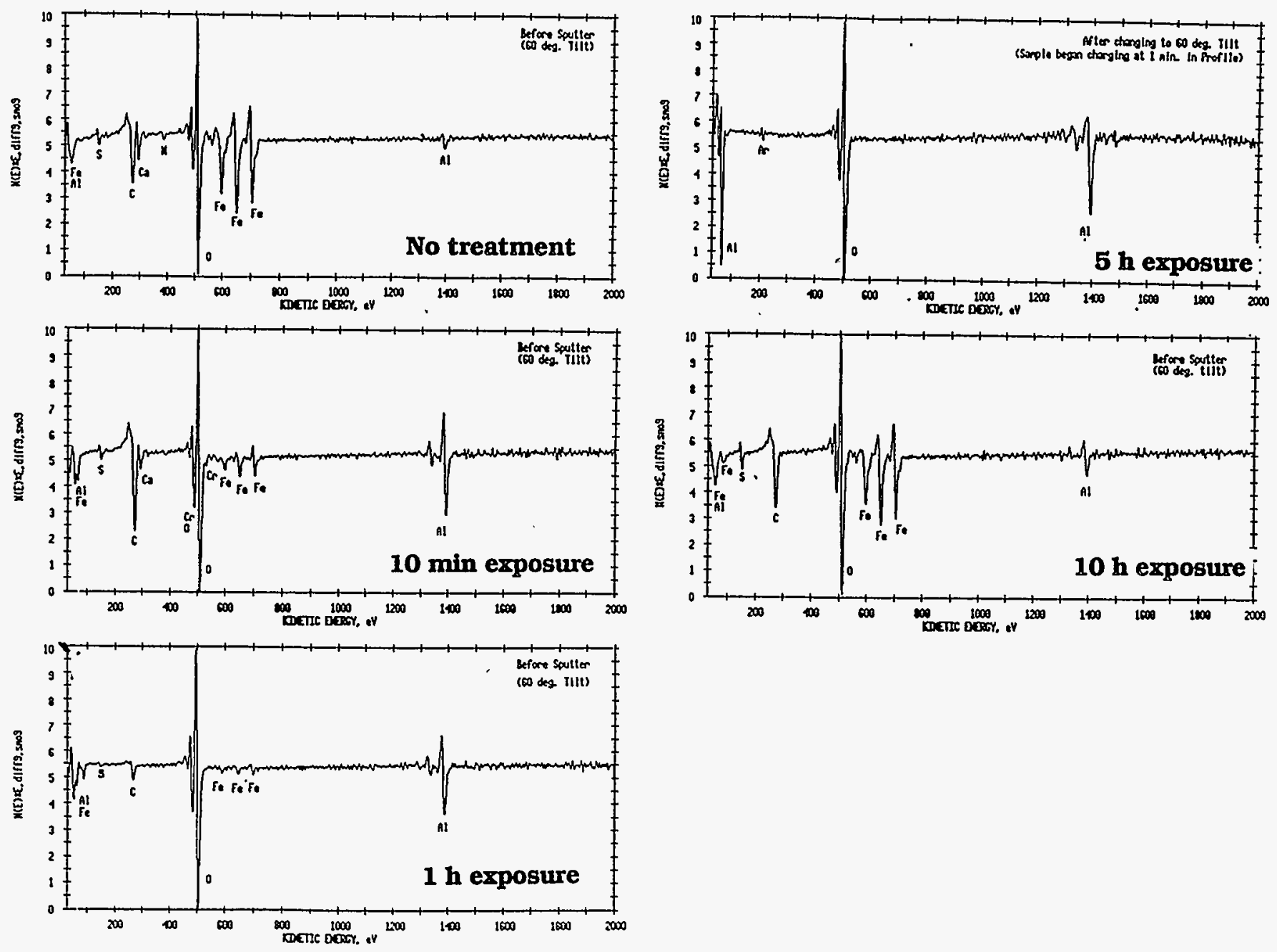

Fig. 9. AES spectra for FA 71 specimen in initial condition and after $10 \mathrm{~min}, 5$, and $10 \mathrm{~h}$ of exposure to high-purity argon at $1000^{\circ} \mathrm{C}$. 

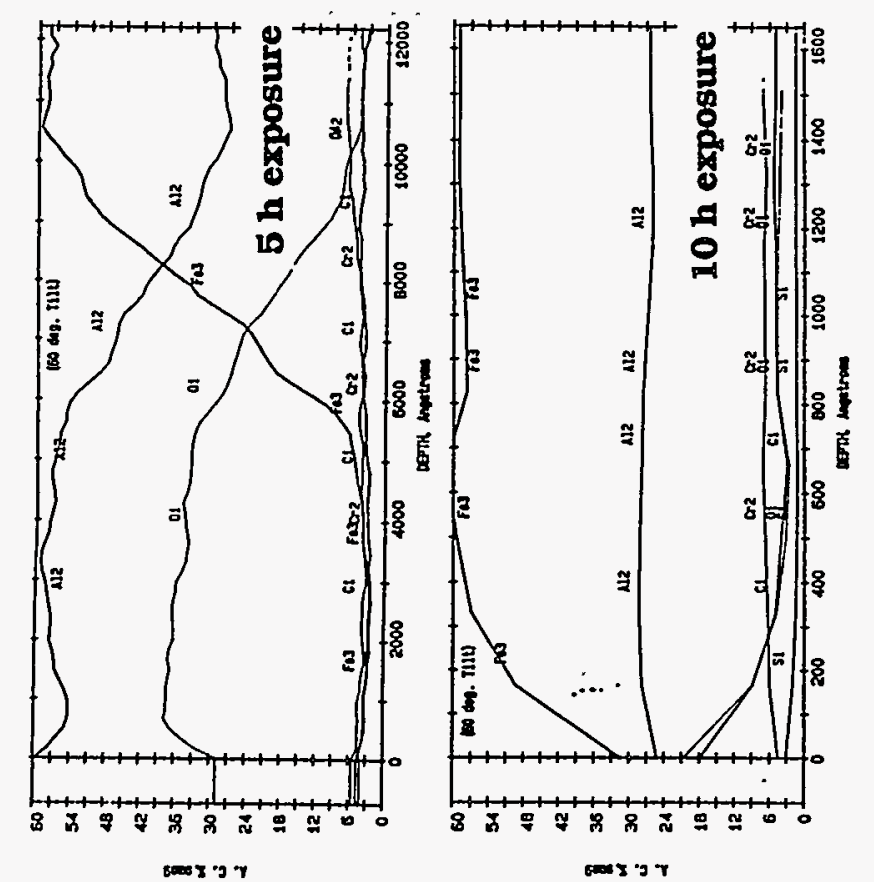

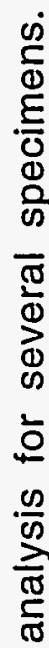

$\underset{\square}{\Psi}$

r



6004 $2 \cdot 2 \cdot y$
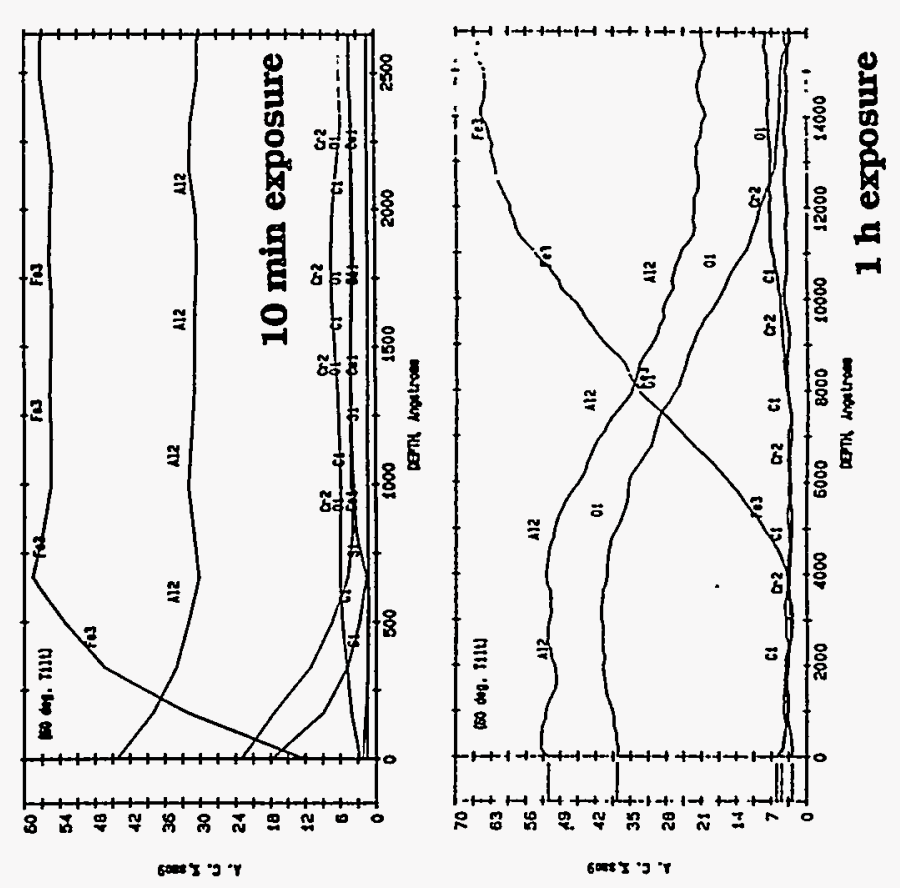

ลิ

足

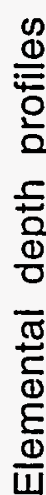

으

i⿺ 
Figure 11 shows elemental concentrations for $\mathrm{Fe}, \mathrm{Al}, \mathrm{O}$, and $\mathrm{S}$ in the surface of Ar-exposed specimens as a function of exposure time. Figure 12 shows the surfaces of FA 71 specimens after $10 \mathrm{~min}$ and 1 and $5 \mathrm{~h}$ of exposure to $\mathrm{Ar}$ at $1000^{\circ} \mathrm{C}$. In $10 \mathrm{~min}$, the alloy showed the grain boundaries of the original material and little or no scaling. In $1 \mathrm{~h}$, the scale was fragmented but analysis showed it to be predominantly alumina. After $5 \mathrm{~h}$ of exposure, the oxide exhibited significant texturing, probably dictated by the original polishing lines of the specimen. The scale exhibited several transverse cracks (i.e., between the parallel grinding lines) and some spallation. However, the scale composition was predominantly alumina. Figure 13 shows photomicrographs of specimens exposed for $10 \mathrm{~h}, 10 \mathrm{~h}$ followed by polishing and further exposure of $5 \mathrm{~h}$, and $10 \mathrm{~h}$ plus polishing and $5 \mathrm{~h}$ of exposure repeated twice. It is evident that the scale is very friable and that spallation is expected. These results confirm the AES results, which showed that scale composition changes from pure alumina to Fe-containing alumina as exposure time increases from 5 to $10 \mathrm{~h}$. Additional experiments are in progress to examine this aspect of scaling and spallation, as well as to evaluate the role of other alloying elements in the scaling/spallation process.
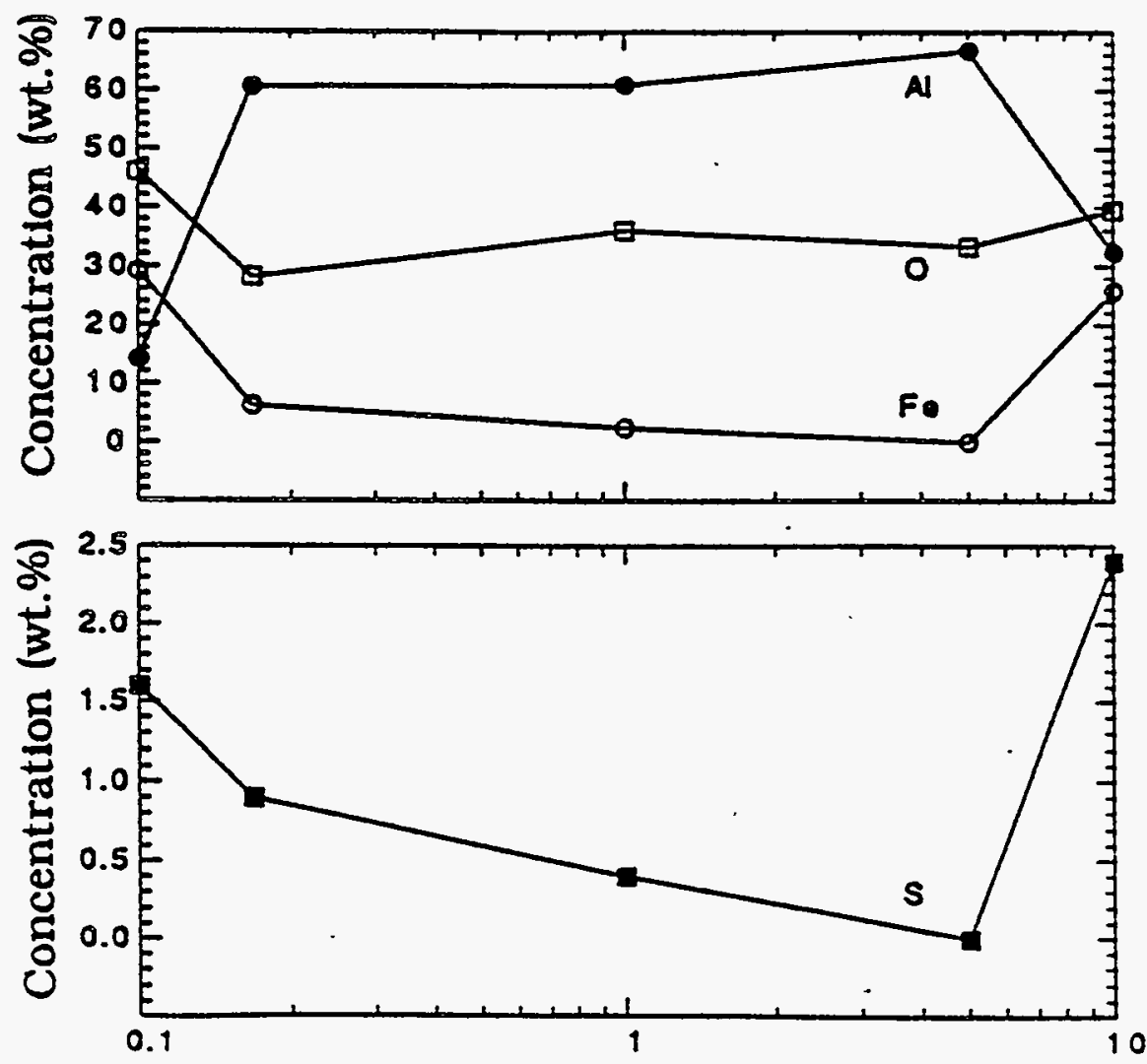

Exposure Time in Argon (h)

Fig. 11. Variation in concentration of $\mathrm{Fe}, \mathrm{Al}, \mathrm{O}$, and $\mathrm{S}$ on surfaces of $\mathrm{FA} 71$ alloy as a function of exposure time in argon at $1000^{\circ} \mathrm{C}$. 

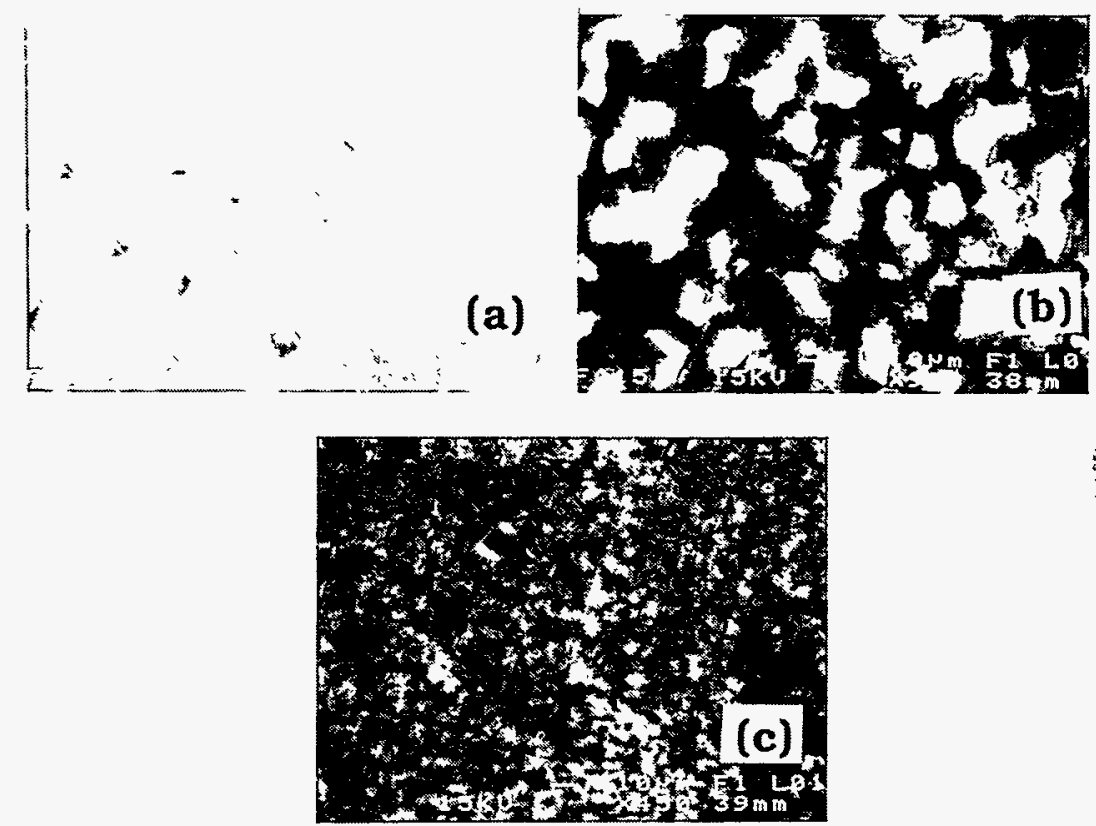

Fig. 12. SEM photomicrographs of surfaces of FA 71 exposed in argon at $1000^{\circ} \mathrm{C}$ for (a) $10 \mathrm{~min}$, (b) $1 \mathrm{~h}$, and (c) $5 \mathrm{~h}$.

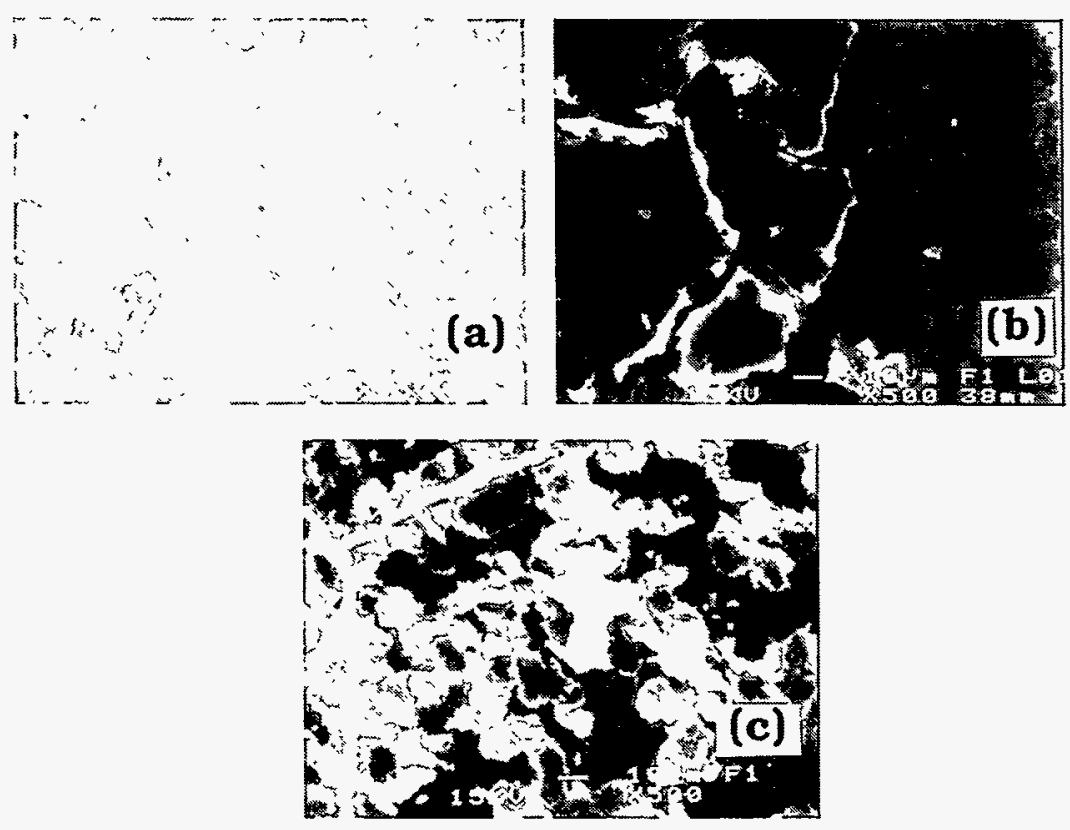

Fig. 13. SEM photomicrographs of surfaces of FA 71 exposed in argon at $1000^{\circ} \mathrm{C}$ for (a) $10 \mathrm{~h}$, (b) $10 \mathrm{~h}$ plus polished and re-exposed for $5 \mathrm{~h}$, and (c) $10 \mathrm{~h}$ plus re-exposure step in (b) repeated twice. 


\section{RAMAN SPECTROSCOPY / RUBY FLUORESCENCE STUDIES}

Figure 14 (left panel) shows a series of Raman spectroscopy measurements from the FA 71 alloy. The top spectrum contains data taken at room temperature before oxidation. The spectrum is featureless because the underlying metal provides no Raman sensitivity in this spectral range. Beginning at $300^{\circ} \mathrm{C}$, the samples were oxidized for $1 \mathrm{~h}$, and a Raman spectrum was taken at room temperature. The 1-h oxidation treatments, followed by room-temperature measurements, were repeated at $100^{\circ} \mathrm{C}$ intervals to a final temperature of $1300^{\circ} \mathrm{C}$. The data in Fig. 14 indicate that by $500^{\circ} \mathrm{C}, \mathrm{Fe}_{2} \mathrm{O}_{3}$ appears prominently in the scale and is replaced by $\mathrm{Al}_{2} \mathrm{O}_{3}$ at $\mathrm{T}>1000^{\circ} \mathrm{C}$. Shown in the right panel of Fig. 14 are room-temperature "ruby line" fluorescence measurements from FA 71 scales after heat treatments of $1 \mathrm{~h}$, beginning at $750^{\circ} \mathrm{C}$, with sequential oxidation at $50^{\circ} \mathrm{C}$ intervals. The fluorescence signal first appears at $750^{\circ} \mathrm{C}$ and grows rapidly in intensity with subsequent oxidation. At temperatures below $950^{\circ} \mathrm{C}$, the peak position displays a red shift, when samples are oxidized at increasingly elevated temperatures. This shift indicates that an increasing compressive strain is developing in the scale. (We note that the red shift of the ruby doublet is used to measure and calibrate hydrostatic pressure in diamondanvil pressure cells.) Strain relief (at room temperature) clearly occurs when reaction temperatures exceed $\approx 950^{\circ} \mathrm{C}$ (probably because of crack formation in the scales), thus signaling the onset of spallation. The $1050^{\circ} \mathrm{C}$ spectrum in Fig. 14 is very similar to that of natural, unstrained ruby; apparently this spectrum identifies scale delamination.

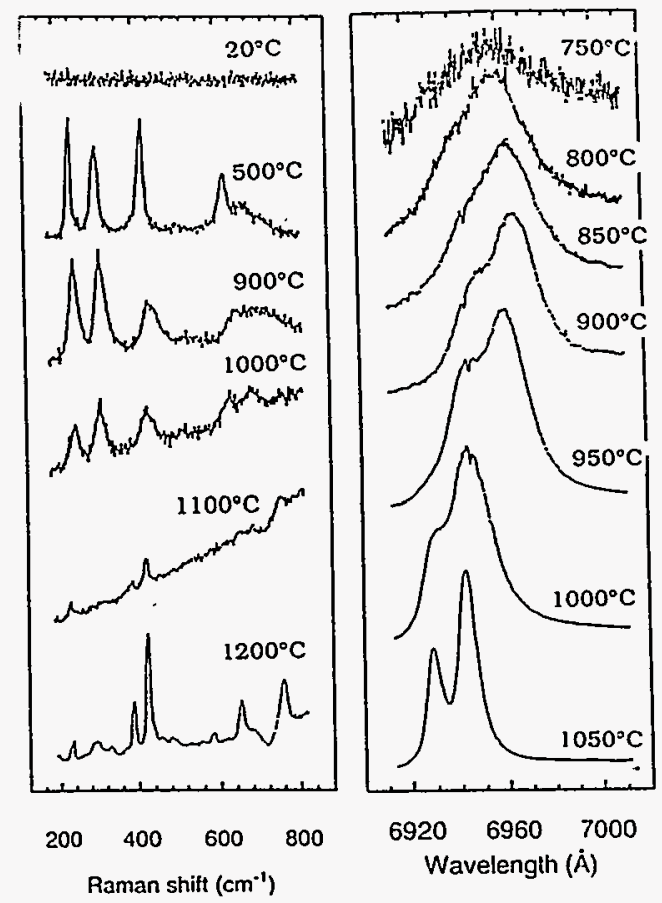

Fig. 14. Raman spectroscopy data obtained for FA 71 alloy after oxidation in air at several temperatures. 
Intensity measurements of the Raman signal for $\mathrm{Fe}_{2} \mathrm{O}_{3}$ and of the ruby fluorescence (data in Fig. 14), plotted vs. oxidation temperature, are shown in Fig. 15. (Raman spectroscopy is not ideal for precise intensity measurements, but dramatic changes occur with oxidation, because observed trends are clearly meaningful.) The presence of iron oxide in the scale is dominant for temperatures up to $\approx 750^{\circ} \mathrm{C}$. At this temperature, $\mathrm{Al}_{2} \mathrm{O}_{3}$ first appears and, for subsequent treatments, dominates the scale. Figure. 15 shows scale evolution through a transient region heavily influenced by $\mathrm{Fe}_{2} \mathrm{O}_{3}$ in the formation of the protective $\mathrm{Al}_{2} \mathrm{O}_{3}$. Curve (a) in Fig. 15, showing a rapid increase in intensity for $\mathrm{T}>1000^{\circ} \mathrm{C}$, is based on data from sample FA 71. Curve (b) is from sample FAL, which contains the reactive element $Z r$, known to provide increased scale adhesion. The rapid growth of Scale (a) relative to Scale (b) is probably due to increased spallation failure with rapid oxidation of exposed substrate.

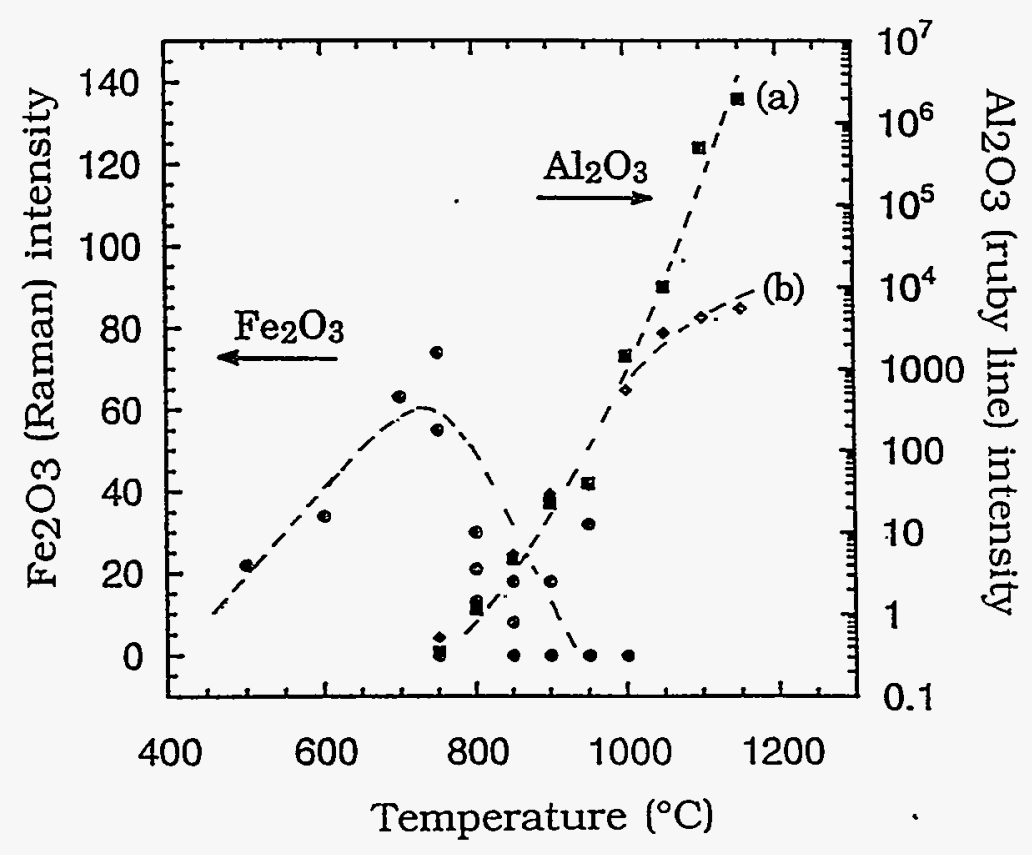

Fig. 15. Raman intensity data for $\mathrm{Fe}_{2} \mathrm{O}_{3}$ from $\mathrm{FA} 71$ and ruby fluorescence data for (a) FA 71 and (b) FAL, as a function of oxidation temperature.

Figure 16 shows measurements of the ruby line peak shift vs. oxidation temperature (data of Fig. 14 for samples FA 71 and FAL). For temperatures below $900^{\circ} \mathrm{C}$, the scales are adherent and the ruby lines show a continuous shift to the red as strain buildup continues. At $950^{\circ} \mathrm{C}$, an abrupt blue shift, apparent in both FA 71 and in FAL, was observed. We are exploring the possibility that this effect might be associated with the $\theta$-to- $\alpha$ phase transition that occurs near $950^{\circ} \mathrm{C}$. With further oxidation at $\mathrm{T}>950^{\circ} \mathrm{C}$, the FA 71 scale quickly shows signs of 
failure, and delamination is apparent at $1050^{\circ} \mathrm{C}$. However, at $>950^{\circ} \mathrm{C}$, the $\mathrm{FAL}$ scale can sustain additional strain without catastrophic failure. The solid line in Fig. 16 denotes the maximum shift and hence maximum strain sustained by the scale. It appears that the maximum sustainable strains occur in $\mathrm{FAL}$ at $1050^{\circ} \mathrm{C}$.

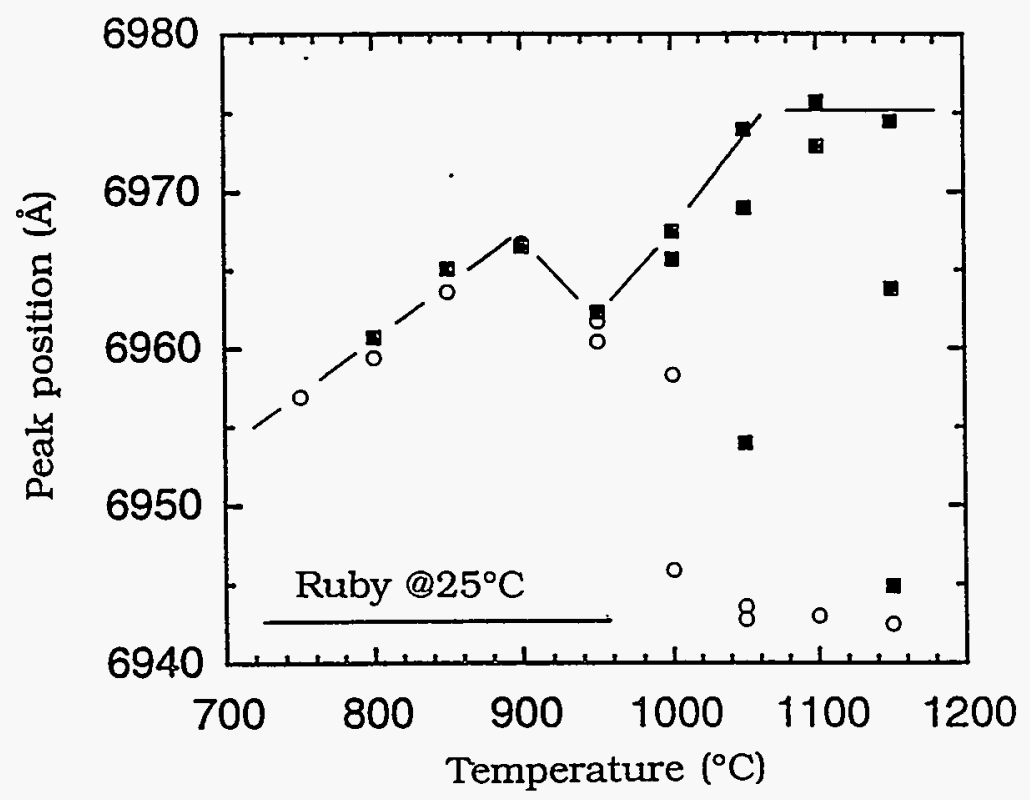

Fig. 16. Data on ruby line peak shift vs. oxidation temperature for FA 71 (open circles) and FAL (solid squares) alloys.

Making use of the known piezospectroscopic coefficients and elastic constants for $\mathrm{Al}_{2} \mathrm{O}_{3}$, we can translate the observed shifts to measurements of compressive strain in the scales. The results are shown in Fig. 17 for FA 71, FAL, and for an alloy of composition Fe-18 wt.\%Cr-5 wt.\% Al. We see that compressive strains as great as $2.5 \%$ are encountered in the alumina scale thermally grown on FAL, based on the measurements at room temperature on the oxidized sample. At the elevated temperatures used to grow the scales, only growth strains should occur (i.e., there is no thermal mismatch between the substrate and scale). However, when samples are cooled to room temperature, additional strain from thermal mismatch will appear. An estimate of this thermal mismatch strain in a thin alumina scale on $\mathrm{Fe}_{3} \mathrm{Al}$ is given by the solid line in Fig. 17. The difference between the solid line (thermal strain) and the strain obtained from the ruby fluorescence might provide an estimate of the growth strain, which, like thermal mismatch strain, is apparently also compressive for FA 71 and FAL.

We observe that the strains, measured at room temperature, in the scale grown on $\mathrm{Fe}-18$ wt.\%Cr-5 wt.\%Al alloy are much lower than the strains in the FA 71 and FAL scales when all scales are grown and measured at comparable temperatures. This reduced strain in the high- $\mathrm{Cr}$ alloy might be related to the peculiar interface morphology known to exist in this alloy. ${ }^{8}$ 


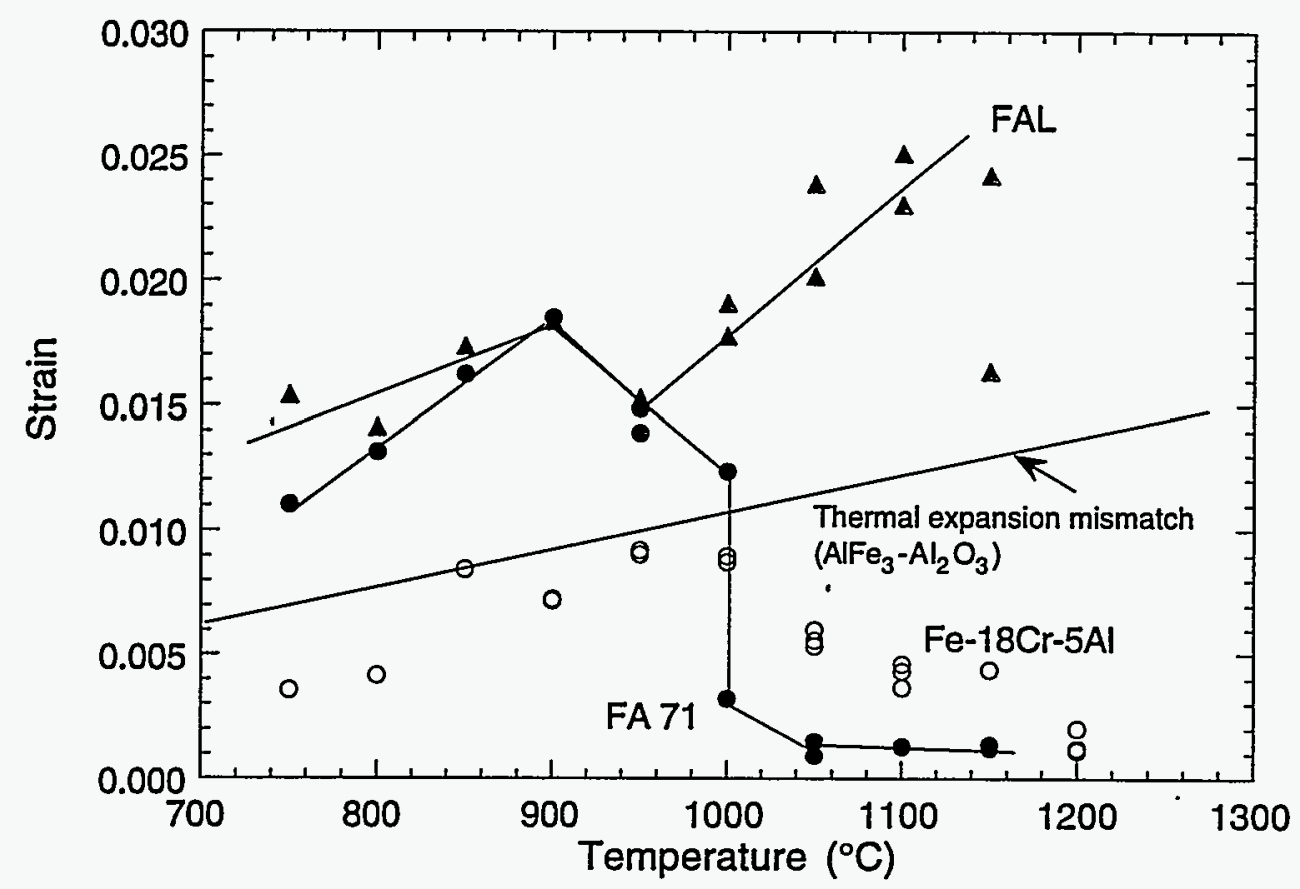

Fig. 17. Strain in thermally grown alumina scales in several. alloys as a function of exposure temperature. Also shown is the strain calculated from thermal expansion mismatch between alumina and AlFe3.

These studies of the ruby line (the $\mathrm{Cr}$ fluorescence line) in alumina scales provide the application of $\mathrm{Cr}$ fluorescence spectroscopy to determine strains and strain gradients in thermally grown scales. Further studies are underway to quantify both the magnitudes and gradients of the strains that occur in the oxide scales.

\section{PLASMA-DEPOSITED ALUMINA}

The specimen with plasma-deposited alumina coating was examined by the Rutherford backscattering (RBS) technique. The RBS spectrum shown in Fig. 18 indicates that the coating contained $\mathrm{Al}$ and $\mathrm{O}$. X-ray diffraction spectrum (see Fig. 19) of the as-coated specimen showed no diffraction peaks (for any of the alumina phases, i.e., $\alpha, \theta, \gamma$ ), indicating that the deposit layer may be amorphous. The specimen with coating on one side only was exposed to air at $1000^{\circ} \mathrm{C}$ for one week. Figure 20 shows SEM photomicrographs of specimen cross sections in ascoated condition and after exposure to air, as well as thermally grown alumina at $1000^{\circ} \mathrm{C}$ in air. The coating was adherent and the coating/alloy interface was fairly smooth. On the contrary, the thermally grown scale on the other side of the same specimen was somewhat ragged, and the scale/metal interface was 
irregular but the scale exhibited good adhesion. Additional experiments are planned with coated specimens to evaluate the microstructures and mechanical integrity of the coatings for comparison with those of thermally grown scales.

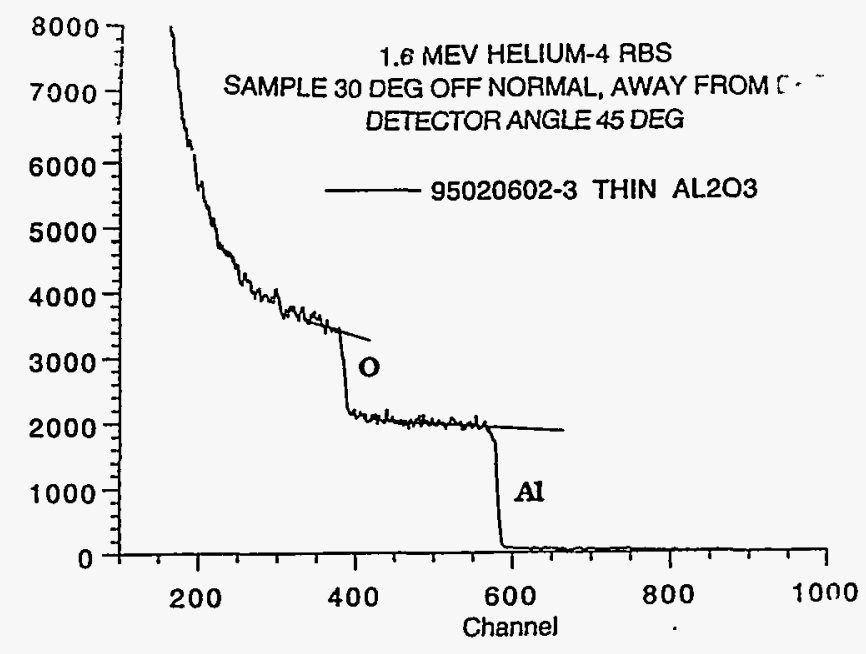

Fig. 18. RBS spectrum for $\approx 0.5 \mu \mathrm{m}$ layer of plasma-deposited alumina.

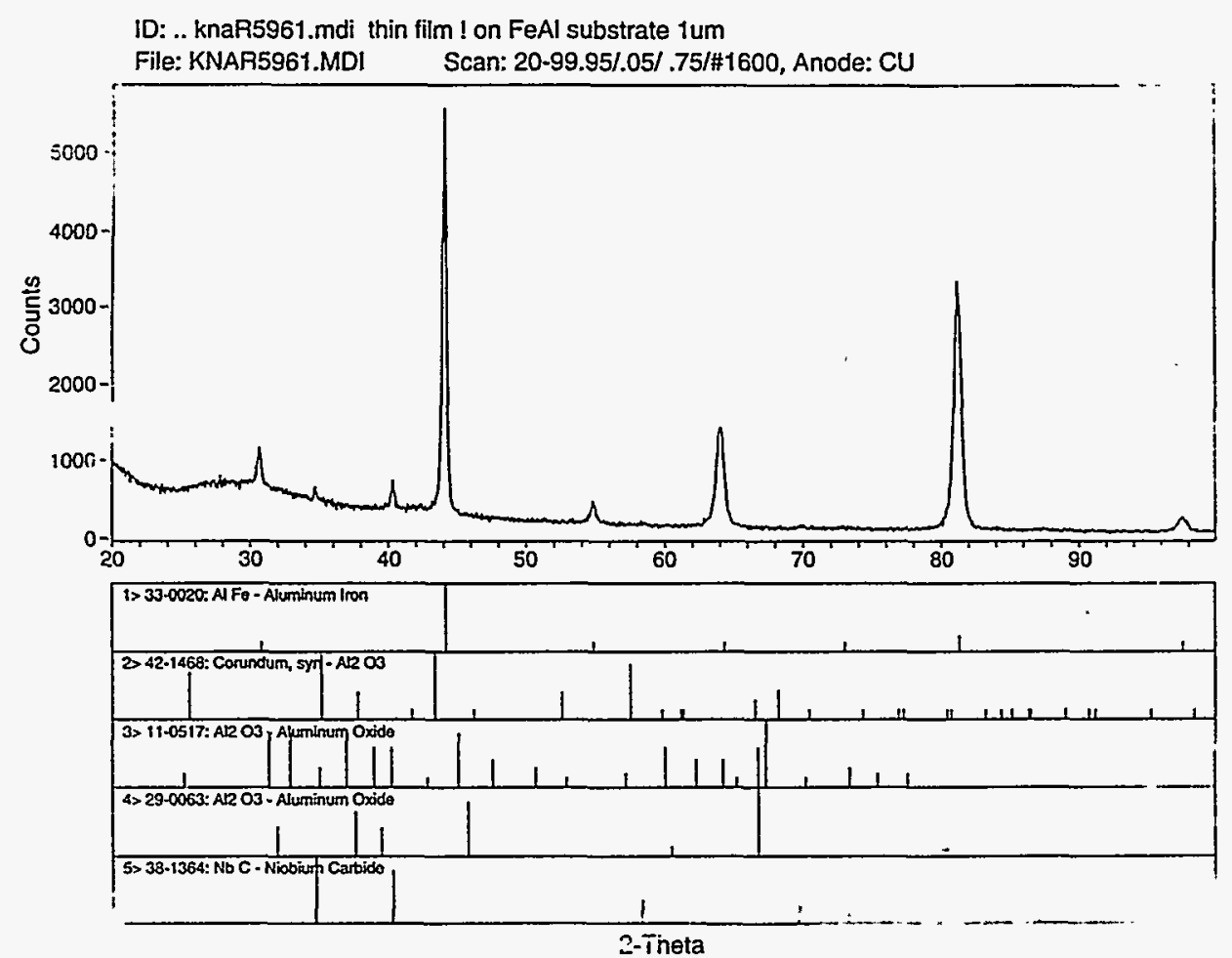

Fig. 19. X-ray diffraction data for $\approx 0.5-\mu \mathrm{m}$ layer of plasma-deposited alumina. 

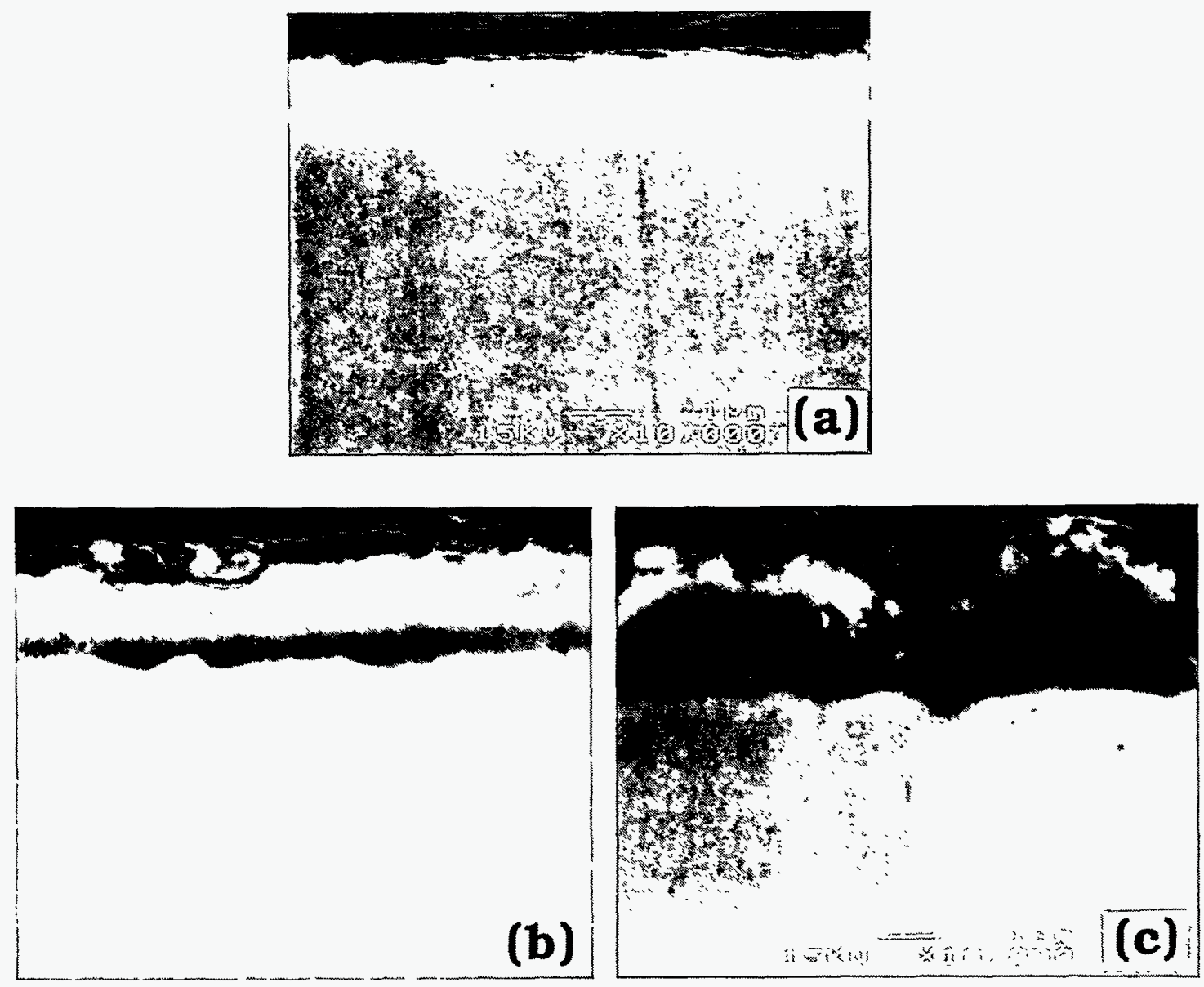

Fig. 20. SEM photomicrographs of specimen with plasma-deposited alumina in (a) as-deposited condition, (b) after exposure to air at $1000^{\circ} \mathrm{C}$, and (c) thermally grown alumina at $1000^{\circ} \mathrm{C}$ in air.

\section{SUMMARY}

A multilaboratory program has been initiated by DOE to develop mechanically reliable oxide scales for high-temperature corrosion resistance. Work at Argonne National Laboratory has focused on alumina-forming alloys, with emphasis on examining the early stages of oxidation of several Fe-Cr-Al alloys and evaluating the segregation behavior of trace elements in the alloys and their role in the scaling and spallation processes that occur during oxidation of these alloys. Preliminary segregation data, obtained by AES, and scaling/spallation data from Raman spectroscopy are presented.

\section{ACKNOWLEDGMENTS}

The authors from Materials Science Division are supported by the DOE Office of Energy Research, Basic Energy Sciences Materials Program. The authors thank V. Sikka and P. Tortorelli of Oak Ridge National Laboratory and P. Y. Hou of Lawrence Berkeley National Laboratory for supplying several of the alloys. D. L. 
Rink assisted in the corrosion tests and microstructural analysis of the exposed specimens. I. Brown of Lawrence Berkeley National Laboratory supplied the plasma-coated specimens. P. Baldo and L. Rehn of Argonne assisted with RBS analysis of coated specimen.

\section{REFERENCES}

1. D. Sigler, The influence of sulfur on alumina grown on Fe-Cr-Al alloys, Oxid. Met., 29 (1/2), 23-43 (1988).

2. G. Smeggil, A. W. Funkenbusch, and N. S. Bornstein, A relationship between indigenous impurities elements and protective oxide scale adherence characteristics, Met. Trans. 17A, 923-932 (1986).

3. D. Sigler, Aluminum oxide adherence on Fe-Cr-Al alloys, modified with Group $I I I-B, I V-B, V-B$, and VI-B elements, Oxid. Met., 32 (5/6), 337-355 (1989).

4. K. Natesan and D. J. Baxter, The role of $\mathrm{Zr}$ and $\mathrm{Nb}$ in oxidation/sulfidation behavior of Fe-Cr-Ni alloys, ANL Report ANL/FE-90/2 (1990).

5. P. Tomaszewicz and G. R. Wallwork, Observations of nodule growth during the oxidation of pure binary iron-aluminum alloys, Oxid. Met., 19 (5/6), 165 (1983).

6. P. F. Tortorelli and J. H. DeVan, Behavior of iron aluminides in oxidizing and oxidizing/sulfidizing environments, J. Mater. Sci. and Engg., A153, 573 (1992).

7. K. Natesan, B. W. Veal, M. Grimsditch, D. Renusch, and A. P. Paulikas, Mechanically reliable surface oxides for high-temperature corrosion resistance, 9th Annual Conf. on Fossil Energy Materials, Oak Ridge, TN (May $16-18,1995$, in press).

8. P. Y. Hou and J. Stringer, Journal de Physique IV, Colloq C9, supplement to Journal de Physique III, 3, 231 (1993). 


\section{Distribution for ANL/FE-95/02}

Internal:

B. Dunlap

C. A. Malefyt

K. Natesan (5)

D. Schmalzer

H. Drucker

A. P. Paulikas

W. J. Shack

W. A. Ellingson

R. B. Poeppel

B. W. Veal

K. Gray

D. Renusch

R. W. Weeks

M. Grimsditch

T. F. Kassner

TIS Files

\section{External:}

DOE/OSTI (2)

ANL Libraries

ANL-E (2)

ANL-W

Chicago Field Office, DOE:

Manager

\section{Energy Technology Division Review Committee:}

H. K. Birnbaum, University of Illinois, Urbana

R. C. Buchanan, University of Cincinnati, Cincinnati, $\mathrm{OH}$

M. S. Dresselhaus, Massachusetts Institute of Technology, Cambridge, MA

S.-N. Liu, Fremont, CA

H. S. Rosenbaum, Fremont, CA

R. K. Shah, General Motors Corp., Lockport, NY

S. Smialowska, Ohio State University, Columbus

R. E. Smith, Altran Corp., Huntersville, NC 




